\title{
Impacto de la evolución de la superficie urbana edificada en el escurrimiento superficial de la ciudad de Tandil, Buenos Aires, Argentina: un escenario de simulación con HEC-RAS
}

Impact of the evolution of the urban built-up area on surface runoff in the city of Tandil, Buenos Aires, Argentina: a simulation scenario with HEC-RAS

María Lorena La Macchia

Centro de Investigaciones Geográficas

Facultad de Ciencias Humanas Universidad Nacional del Centro Provincia de Buenos Aires (UNICEM) Instituto de Geografía, Historia y Ciencias Sociales Consejo Nacional de Investigaciones Científica y Técnicas (CONICET)

Argentina

llamacchia@fch.unicen.edu.ar

Santiago Linares

Centro de Investigaciones Geográficas

Facultad de Ciencias Humanas Universidad Nacional del Centro Provincia de Buenos Aires (UNICEM) Instituto de Geografía, Historia y Ciencias Sociales Consejo Nacional de Investigaciones Científica y Técnicas (CONICET)

Argentina

slinares@fch.unicen.edu.ar

\section{RESUMEN}

El siguiente artículo forma parte de una investigación en curso que estudia y profundiza los procesos que intervienen en la modelización hidrodinámica de una cuenca urbana. Este concepto parte de considerar la construcción de un modelo hidrológico que tiene en cuenta principalmente la superficie de drenaje y un modelo hidráulico definido por las características y parámetros de la infraestructura que presenta la cuenca. 
En los últimos diez años, los modelos hidrológicos han sido cada vez más utilizados para evaluar, comprender y analizar la dinámica de escurrimiento en los sistemas de cuencas posibilitando la predicción de escenarios a corto y mediano plazo a partir de la simulación de eventos de diferentes intensidades e implicancias socioespaciales.

El objetivo de este trabajo es construir un modelo matemático de modelización de crecidas para la cuenca urbana de la ciudad de Tandil mediante la herramienta HECRAS. Los parámetros que definen la construcción del modelo numérico dependen de la topografía o Modelo Digital del Terreno, la red de drenaje, los modelos de expansión urbana que fijaron la configuración territorial actual del espacio urbano, los coeficientes de rugosidad diferenciando las zonificaciones dentro de la ciudad y el caudal de lluvia determinado por su intensidad y velocidad. En este caso, la única variable "input" que no se utilizó fue la red geométrica de drenaje. A partir de la herramienta implementada fue posible realizar simulaciones para los años 1996 y 2011. Su análisis permitió conocer el efecto de los cambios de coberturas del suelo en el escurrimiento superficial, indispensable para evaluar y recomendar políticas de gestión y planificación de algunos factores como por ejemplo, el tratamiento, mantenimiento y extensión de la red de desagües pluviales, restricciones a la densificación en la edificación, generación de nuevos espacios verdes que actúen como amortiguadores de infiltración, entre otras medidas semiestructurales a la planificación urbana vigente.

PALABRAS CLAVE: Modelización hidrodinámica - Cuenca urbana - Tandil - HEC-RAS

\section{ABSTRACT}

The following article is part of an ongoing investigation that studies and deepens the processes involved in the hydrodynamic modeling of an urban basin. This concept starts from considering the construction of a hydrological model that mainly takes into account the drainage surface and a hydraulic model defined by the characteristics and parameters of the infrastructure that the basin presents.

In the last ten years, hydrological models have been used to assess, understand and analyze runoff dynamics in basin systems, making it possible to predict short and medium-term scenarios from the simulation of events of different intensities and socio-spatial implications.

The objective of this work is to build a mathematical model of flood modeling for the urban basin of the city of Tandil using the HEC-RAS tool. The parameters that define the construction of the numerical model depend on the topography or Digital Land Model, the drainage network, the urban expansion models that established the current territorial configuration of the urban space, the roughness coefficients differentiating the zoning within the city and the rainfall flow determined by its intensity and speed. In this case, the only "input" variable that wasn't used was the 
geometric drainage network. From the implemented tool, it was possible to carry out simulations for the years 1996 and 2011. Their analysis allowed us to know the effect of the changes in land cover on the surface runoff, essential to evaluate and recommend management policies and planning of some factors. For example, the treatment, maintenance and extension of the storm drainage network, restrictions on densification in the building, generation of new green spaces that act as infiltration buffers, among other semi-structural measures to current urban planning.

KEYWORDS: Hydrodynamic modeling - Urban basin - Tandil - HEC-RAS

\section{INTRODUCCIÓN}

Los abordajes y dimensiones de análisis desde la gestión integral del riesgo requieren pensar los impactos que los problemas espaciales urbanos acontecen en el territorio y redefinen la dialéctica sociedad-naturaleza. Las políticas de intervención derivadas del monitoreo, gestión y control para la construcción de ciudades sostenibles necesitan potenciar una mirada integral e interdisciplinar para trabajar y analizar las interrelaciones de estos procesos desde una óptica compleja.

Un sistema complejo, en términos de Rolando García (2006), se define como la representación de un recorte de la realidad, la cual es entendida como una totalidad organizada, integrada por unidades complejas, llamadas subsistemas, que no pueden estudiarse aisladamente. De esta manera, es fundamental su estudio teniendo en cuenta cada uno de los elementos que entran en contradicción en los estudios de riesgo: el subsistema social y el natural. Ambos conforman un par dialéctico en permanente proceso de definición y redefinición.

La gestión del riesgo constituye una ecuación de los conceptos de amenaza, vulnerabilidad y riesgo que implica el análisis de distintas dimensiones de los fenómenos (Herzer, 2002; Carballo y Goldberg, 2014; Natenzon 1998). El proceso de urbanización y expansión urbana de las ciudades, la planificación y modificación de usos del suelo, el desarrollo de infraestructura, trae aparejadas las respuestas del ambiente y el ecosistema urbano a esas acciones generando riesgos y problemas ambientales.

El análisis de inundaciones y anegamientos (Ferrando y Francisco, 2006) representa un tema de investigación siempre vigente en la Geografía (Johnston, Gegory y Smith, 
1981; López Trigal, 2015) y constituye una problemática socioeconómica y ambiental intrínsecamente ambivalente, dado que es la misma acción que la sociedad ejerce sobre el territorio, la que incrementa los efectos negativos de dicha eventualidad, la cual dinamizada por las actividades económicas, antropización del medio natural y pauta de localización de la población en áreas urbanas, termina por modificar las características de escorrentía de las cuencas mediante cambios de usos del suelo y el reemplazo de las coberturas naturales por coberturas impermeables, intensificando con ello el riesgo a inundaciones (Melesse y Wang, 2007).

En la llanura pampeana Fuschini Mejia (1998) considera que las inundaciones pueden clasificarse en inundaciones por desborde, por anegamiento y mixtas. En muchas zonas, las características geomorfológicas del territorio provocan que las planicies sean el escenario del desborde de los cursos de agua que, en épocas de excedentes, producen inundaciones hacia áreas laterales, fenómenos conocidos como almacenamiento lateral, que puede cubrir campos y tener lento movimiento. Las inundaciones por anegamiento se desarrollan en áreas sin pendiente en las cuales el agua queda estancada por periodos de tiempo, según la magnitud del evento y, por último, las mixtas ocurren por la combinación de ambas, por desborde y anegamiento. Profundizando estas características, Adriana Pereyra (2014) destaca que las inundaciones y los anegamientos pueden ser upstream floods, definidas como inundaciones aguas arriba, producto de intensas precipitaciones en cortos periodos de tiempo en zonas de pendiente alta o zonas montañosas y downstream floods consecuencia de tormentas de larga duración en grandes extensiones, propias de ambientes de baja pendiente o zonas llanas. En estas aparecen las flashfloods, propias de la rapidez con la que acontecen. Según la autora en muchas ocasiones se contemplan la dinámica natural del área y de la cuenca, obviando los procesos de valoración y uso del territorio, altamente vulnerable. Además, no se reflexiona sobre las transformaciones en la cuenca mediante la construcción de canales y otras obras que modifican el comportamiento y dinámica del sistema.

En palabras de Rolando García (2006) hablamos de una problemática compleja donde el estudio de los problemas espaciales urbanos permite pensar en los procesos transversales (políticos, económicos, institucionales, sociales y ambientales) que parten de un modelo de desarrollo cuyo principal objetivo es la construcción de un espacio productivista y dinámico que no mide los impactos que 
generan en el territorio y en la relación sociedad-naturaleza. Por ello, es necesario un diagnóstico integrado para proponer acciones concretas y políticas de intervención orientadas a las propiedades del sistema y los subsistemas involucrados, analizando su vulnerabilidad y resiliencia y considerando su dinámica y evolución temporal a diferentes escalas.

Cuando analizamos los subsistemas que intervienen en un proceso de inundación, además del social, el económico y el político institucional, encontramos el natural: el territorio. En esta línea, González, Torchia y Viand (2015:33) mencionan las precipitaciones intensas o prolongadas, la crecida de un río, la marea de tormenta, el oleaje, la falla de alguna estructura hidráulica, la capacidad de absorción de los suelos, la insuficiente capacidad de descarga de los cursos de agua y la pendiente del terreno, como las más destacadas. Pero en todos los casos conviven las interrelaciones entre todos los subsistemas.

Específicamente sobre las ciudades, las autoras señalan que las inundaciones más características tienen que ver con la ocurrencia de precipitaciones intensas, las cuales saturan la capacidad del sistema de desagüe pluvial, como consecuencia de un aumento del escurrimiento superficial producto de una disminución de la infiltración por superficies pavimentadas y edificaciones (González, Torchia y Viand, 2015:34).

Los procesos de ocupación y transformación del espacio nos permiten entender el modelo de desarrollo existente en las áreas urbanas y la falta de una lógica coherente con las premisas del desarrollo sustentable sobre todo para explicar el problema de las inundaciones. Conceptos clave como el de justicia espacial, equidad, capacidad de carga y valoración ecosistémica del paisaje urbano se encuentran sujetos a intereses y actores que definen políticas públicas en pos de costos ambientales como la densificación urbana no planificada, urbanización en áreas de protección natural o paisajística y reducción de áreas verdes que impactan decisivamente en la alteración del sistema hidrológico e hidráulico modificando el drenaje superficial y subsuperficial y derivando en la construcción de obras de infraestructura, rellenos, canalizaciones y entubados no proyectados.

Tucci (2005:90-91) va a describir detalladamente las alteraciones que la urbanización produce al ciclo hidrológico. En términos resumidos constaría de la siguiente 
secuencia: comenzando por la reducción de la infiltración del suelo, la cual provoca que el volumen de agua que no infiltra permanezca en la superficie, aumentando con ello la escorrentía superficial; por la reducción de la infiltración, el acuífero tiende a disminuir el nivel del nivel freático (especialmente cuando el área urbana es muy extensa) reduciendo el flujo subterráneo; y finalmente, dada la sustitución de la cobertura natural por zonas impermeables, hay una reducción de la evapotranspiración, ya que la superficie urbana no retiene agua como la cubierta vegetal y no permite evapotranspiración como ocurre por el follaje y el suelo. Él mismo autor enfatiza que este proceso de alteración del ciclo hidrológico, y posterior anegamiento, es sensible también a la falta de control del espacio urbano e infraestructura hídrica, compuesta esencialmente por sistemas de abastecimiento de agua, alcantarillado sanitario, red de desagüe pluvial y tratamiento de residuos sólidos (Tucci, 2005:9).

Desde un punto metodológico, existe una vasta y creciente experiencia en implementar herramientas geotecnológicas que permitan analizar, evaluar, modelar y brindar soluciones ante el riesgo a inundaciones y anegamientos urbanos. Algunos antecedentes los podemos mencionar en los trabajos de DeVantier, y Feldman, 1993; Vanneuville et al. 2003; Henríquez Ruiz, 2009; Ellis et al. 2012; Sanchez y Lastra, 2011; Fernández et al. 2018 y Collazos et al. 2018. En estos casos se trabaja sobre la elaboración de modelos hidrológicos e hidráulicos unidimensionales o bidimensionales para analizar el comportamiento del escurrimiento superficial en los ejes del cauce o arroyo principal para cada recorte espacial y bajo un hidrograma o caudal de un evento.

Scioli (2009) en su trabajo estudia y evalúa el aporte desde los distintos modelos hidrológicos implementando y calibrando el que más se ajusta en áreas de llanura. Su objetivo consiste en analizar el movimiento multidireccional del agua sobre el terreno y evaluar la variabilidad de la superficie con el aporte de los modelos digitales de elevación (MDE) SRTM.

La diversidad de trabajos se reduce, por un lado, a la propuesta de diferentes modelos de simulaciones hidrológicas, hidráulicas o ambas para distintos tipos de relieve y al aporte de los modelos digitales de elevación (MDE) y a la extracción de parámetros morfométricos de la cuenca para incorporarlos a las modelizaciones. 
Teniendo en cuenta el recorrido bibliográfico de la problemática, la mayoría de los aportes provienen desde las ciencias exactas, como las ciencias de la ingeniería, física, agrimensura e hidráulica y es, en este sentido, donde es necesario considerar una visión entre disciplinas considerando la gestión, planificación y monitoreo del territorio desde el campo de la geografía aplicada. Es decir, analizar la relación sociedad-naturaleza y su complejidad para la construcción de ciudades sostenibles. Los trabajos más afines a nuestra disciplina están vinculados a estudios de riesgo. Estas investigaciones refieren al diagnóstico del sistema natural actual de las ciudades medias, a su vulnerabilidad y a la elaboración de cartas de riesgo hídrico para generar estrategias de intervención respecto a su posterior mitigación, gestión y evaluación.

La aplicación de geotecnologías para el desarrollo de modelos predictivos, monitoreo y mitigación de inundaciones permite dar respuesta y tomar decisiones en el desarrollo de políticas públicas que eviten los problemas de anegamiento en ciudades bonaerenses, pero en muchos casos es difícil contar con fuentes de información debido a la falta de datos disponibles a diferentes escalas, a la forma de compatibilizar la información espacial y temporal, a la ausencia de una secuencia procedimental fácilmente replicable y a una norma de interpretación de los resultados estandarizada. Este artículo persigue ese propósito de transferencia, desde un punto de vista metodológico, describir fuentes accesibles de información en base a los recursos disponibles, indicar etapas generales del procedimiento y norma de interpretación estandarizada de resultados como una primera aproximación al problema. Como objetivo final se pretende poder clasificar zonas de peligro o amenaza en base a la determinación de escalas que plantea la guía AEMI 2013 utilizando mapas de velocidad y profundidad del escurrimiento sobre el terreno. Si bien la guía conjuga ambos mapas en curvas de mayor o menor vulnerabilidad y determina grados de peligro y afectación en lo urbano, en este trabajo, solamente se analizan los resultados del producto de los mapas de $\mathrm{D} \times \mathrm{V}$ (depth por velocity).

En la ciudad de Tandil, según investigaciones precedentes (La Macchia, 2015), existen zonas de mayor peligro que se localizan, en primer lugar, hacia el norte, noroeste y noreste caracterizados por zonas de baja pendiente, con escasa infiltración del suelo y una velocidad y sentido de escurrimiento hacia la misma 
dirección. Esta zona, ha evidenciado un gran crecimiento urbano y se ha expandido considerablemente entre los años 1991 y 2011, lo cual, provoca impactos en el proceso de escorrentía superficial.

En segundo lugar, el sur, suroeste y sureste de la ciudad constituye otra de las zonas de amenaza ante la intensidad y duración de un evento. Si bien estas áreas se ven favorecidas por el emplazamiento del piedemonte serrano, que actúan como superficies de infiltración y drenaje del agua, el problema radica en la velocidad y multidireccionalidad con que se desarrolla el escurrimiento superficial. Esta área también se ha expandido en los últimos años y la dinámica del mercado inmobiliario junto a su especulación han significado el aumento de las actividades vinculadas a la recreación y oferta de complejos hoteleros destinado al consumo de las clases de altos ingresos.

En tercer lugar, otra zona de impacto es el área central de la ciudad enmarcada por la presencia de los entubamientos del A을 Blanco y A을 Del Fuerte. Las precipitaciones desde aguas arriba y el aumento de su velocidad en superficie impactan tanto en las zonas aledañas de ambos conductos como sobre los ramales y ejes de circulación. El aumento del tiempo de retención se produce debido a la saturación del sistema de drenaje y la insuficiencia de los sumideros para captar y drenar el agua de lluvia. Asimismo, se debe tener en cuenta la gran densificación que se manifiesta en el área central y la baja o nula infiltración del suelo que impacta aguas abajo.

Este artículo describe un método para elaborar un modelo bidimensional de escurrimiento superficial en la ciudad de Tandil, como base para detectar amenazas de inundación en un área urbana, esto es, identificación del origen, área de afectación potencial, intensidad, duración, temporalidad y probabilidad de ocurrencia en zonas y áreas cercanas. Los principales inputs estarán determinados por el modelo digital del terreno, el parcelamiento del área urbana, la evolución de la superficie edificada para los años 1996 y 2011 y algunos parámetros hidrológicos e hidráulicos determinados para toda la cuenca. Como resultados se obtienen escenarios de profundidad y velocidad del agua superficial para los dos momentos analizados (1996 y 2011), ajustados según sus respectivos coeficientes de rugosidad y parámetros hidrológicos. 
La guía AEMI 2013 permite cuantificar el peligro y establecer escalas de zonas de mayor a menor vulnerabilidad según la multiplicación de los escenarios de profundidad y velocidad. La determinación de estas áreas contribuirá a monitorear y mitigar los impactos de eventos impredecibles, reducir la incertidumbre y servirán como base para la formulación de planes, programas y proyectos en el marco de la gestión integral del riesgo a inundaciones.

\section{MATERIALES Y MÉTODOS}

El presente trabajo fue desarrollado empleando la extensión HEC-GeoRAS en su versión 10.2 para ArcGIS 10.2. Es una herramienta desarrollada conjuntamente por el Hydrologic Engineering Center (HEC) del United States Army Corps of Engineers y el Environmental System Research Institute (ESRI). Básicamente es un conjunto de procedimientos, herramientas y utilidades especialmente diseñadas para procesar datos georreferenciados que permiten bajo el entorno de los Sistemas de Información Geográfica (SIG), facilitar y complementar el trabajo con HEC-RAS 5.0.3.

La aplicación se desarrolla sobre la ciudad de Tandil, localizada al sudeste de la provincia de Buenos Aires, Figura 1. Se encuentra emplazada en un relieve de piedemonte y valle distal, rodeada por sierras bajas que forman parte del Sistema de Tandilia, lo que le otorga gran belleza paisajística y destacada importancia geológica (Linares, 2012). Desde su origen la ciudad se ubicó en el interfluvio de los Arroyos Del Fuerte y Blanco, y desde ese punto, la ciudad se ha extendido en forma radial hacia el noroeste, norte, noreste y este donde predomina la llanura, y por ende la disponibilidad de suelo edificable y a bajo costo. En las últimas décadas, los cambios sociales y nuevas pautas residenciales generaron una fuerte demanda de construcciones residenciales y alojamiento orientado al turismo hacia el piedemonte serrano, alterando el tradicional marco natural del cordón serrano localizado al suroeste y sur de la ciudad.

Para ejecutar dicha modelización fue necesario contar con los siguientes insumos: 
1) Modelo Digital del Terreno (MDT) de la ciudad de Tandil sobre la base del Modelo Digital de Elevación de la misión SRTM de 12,5 metros de resolución espacial ${ }^{1}$. Para ello se procedió a superponer la capa de parcelas vectoriales del catastro del área urbana y complementaria de la ciudad por encima del MDE, exagerando su escala vertical 5 metros, Figura 2. Este proceso permitió forzar durante la simulación del evento, que el agua escurra sobre la red de drenaje urbano y las principales vías de comunicación, como regularmente ocurre en la realidad.

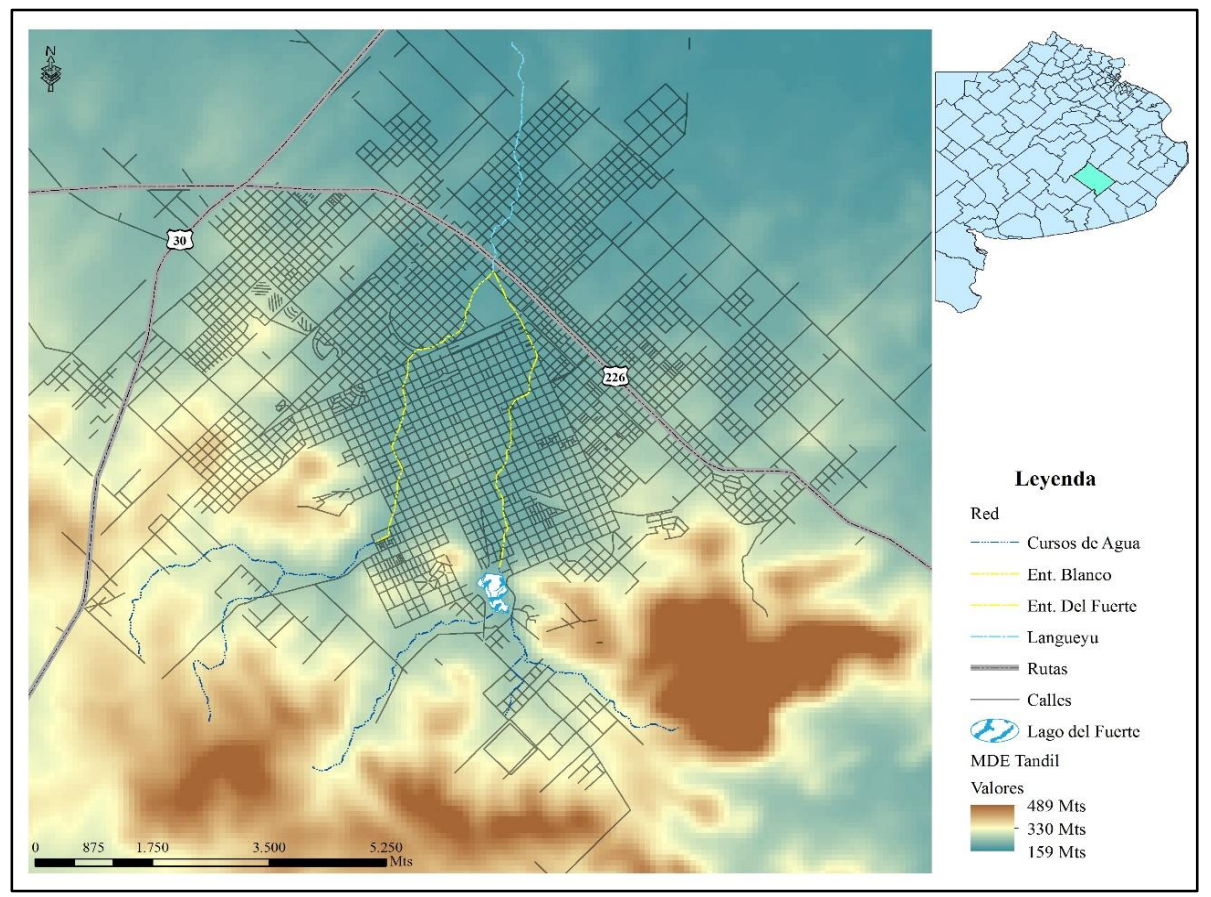

Figura 1. Situación geográfica ciudad de Tandil, Buenos Aires, Argentina Fuente: La Macchia, 2015.

\footnotetext{
${ }^{1}$ Disponible en: https://vertex.daac.asf.alaska.edu/\#
} 


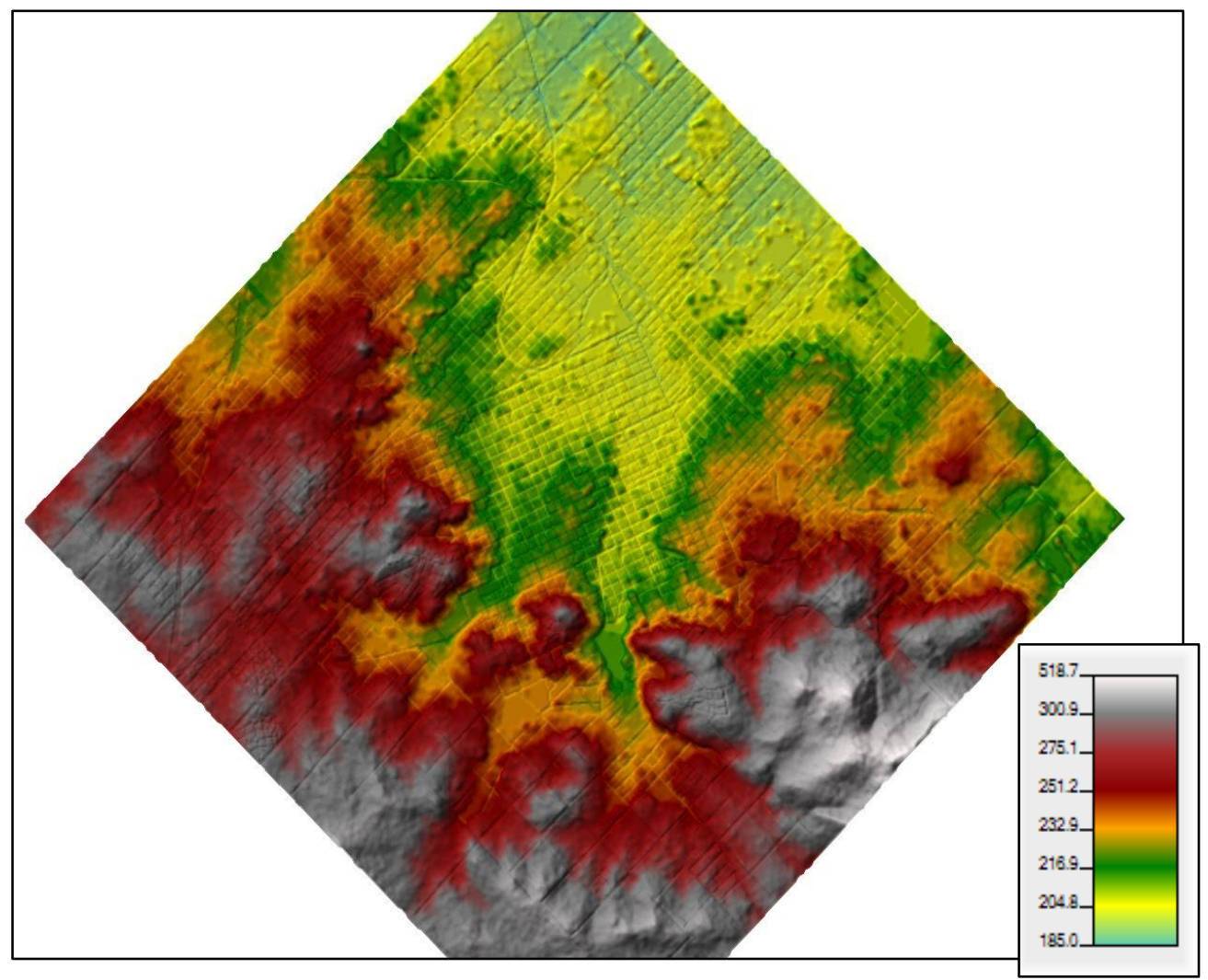

Figura 2. Modelo Digital del Terreno de la Ciudad de Tandil Fuente: Elaboración personal mediante procesamiento en RAS Mapper. HEC-RAS 5.0 .3

2) Mapas ráster con diferentes porcentajes de superficie edificada en la cuenca del Arroyo Langueyú de la ciudad de Tandil obtenido mediante el procesamiento de mezclas espectrales en base a imágenes satelitales Landsat de $30 \mathrm{~m}$ de resolución espacial, Figuras 3 y 4 . Se escogieron dos imágenes Landsat 5 TM con fechas: 30 de octubre de 1996 y 24 de octubre de 2011, correspondientes a la escena Path 225 y Row $86^{2}$. Se seleccionaron las bandas $1,2,3,4,5$ y 7 , que corresponden al espectro visible, infrarrojo cercano y medio. El método para generar los clasificadores de

\footnotetext{
${ }^{2}$ Obtenidas de la página web del U. S. Geological Survey (http://glovis.usgs.gov/)
} 
superficie edificada implicó cuatro etapas, las cuales se describen en Linares y Picone (2018). Como resultado se obtienen cuatro tipos de categorías de coberturas según densidad de superficie edificada, (1) sin edificaciones, (2) baja densidad de edificaciones. (3) media densidad de edificaciones y (4) alta densidad de edificaciones.

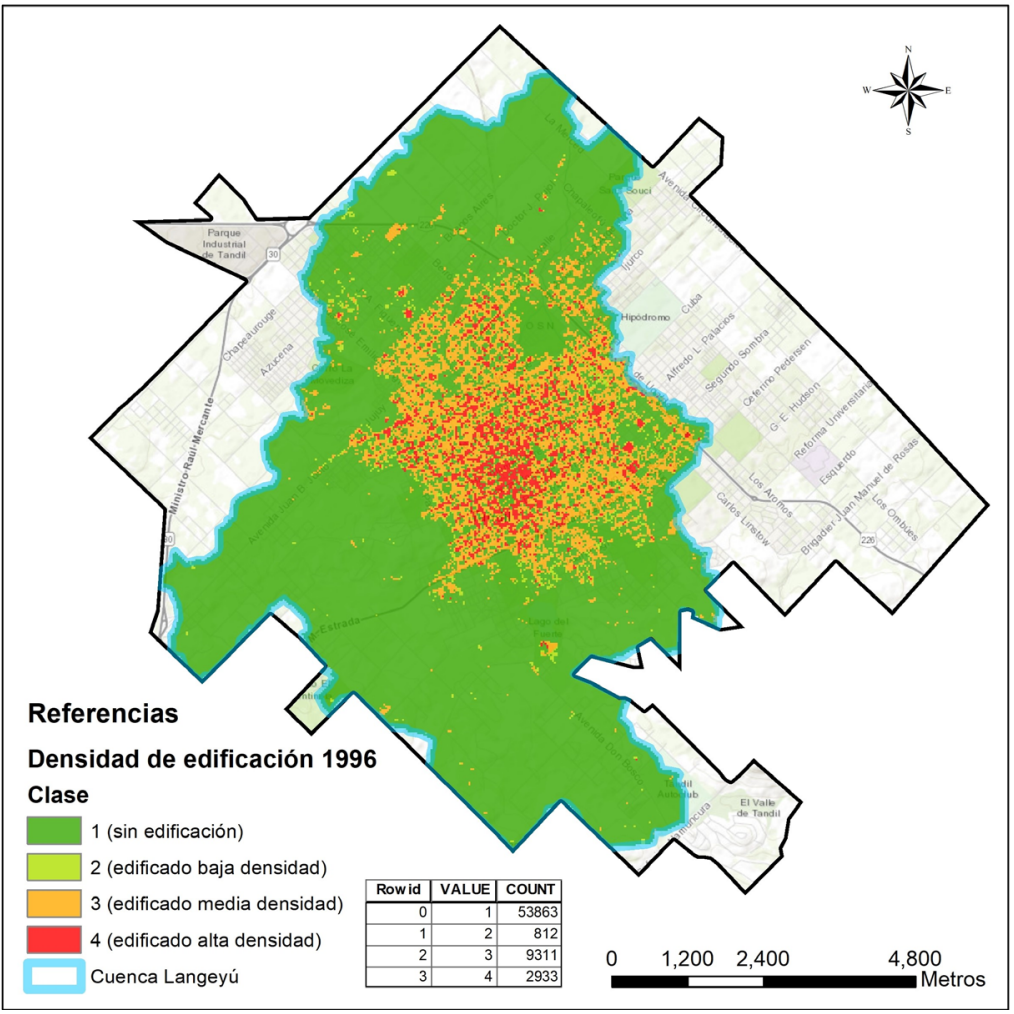

Figura 3. Densidad de edificación en la Ciudad de Tandil. Cuenca urbana Langeyú (año 1996) Fuente: Elaboración personal mediante ArcGIS 10.2. 


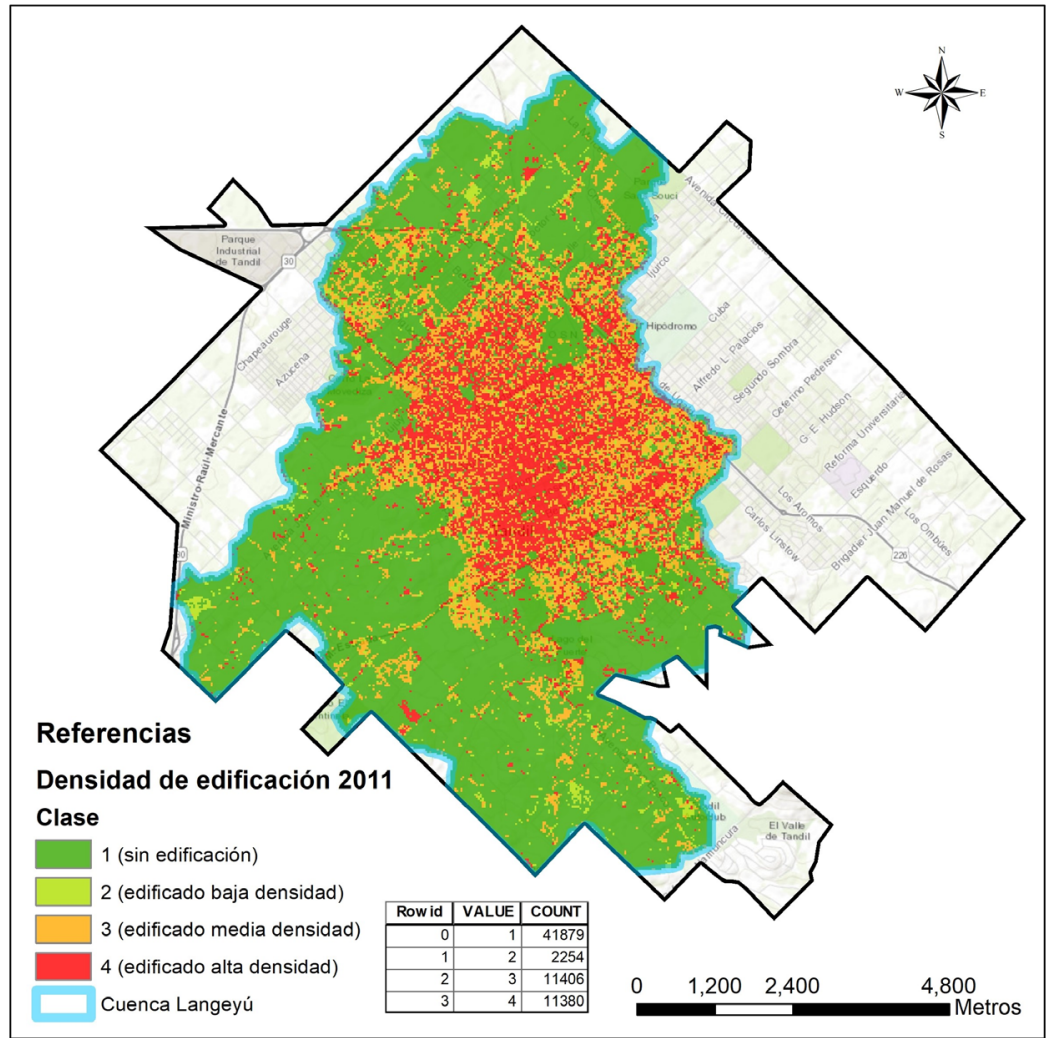

Figura 4. Densidad de edificación en la Ciudad de Tandil. Cuenca urbana Langeyú (año 2011) Fuente: Elaboración personal mediante ArcGIS 10.2.

Las conclusiones arribadas a partir del trabajo publicado en Linares y Picone (2018) permiten explicar que la superficie de infiltración (categoría 1 en la clasificación) era en 1996 de 53863 pixeles y para 2011 de 41879 pixeles. Es decir, se observa una significativa disminución de 53863 - $41879=11984$ pixeles. Si cada pixel posee una resolución espacial de 30 metros, entonces su superficie equivale a $900 \mathrm{~m}^{2}$, deduciendo que la cantidad de hectáreas de infiltración pérdida es igual a $11984 \mathrm{x}$ $900=10785600 \mathrm{~m}^{2}=1078,56$ ha. Este insumo es central para ingresarlo como superficie urbana edificada en los escenarios planteados para este trabajo y poder 
asignarle diferentes coeficientes de rugosidad para que influya en la modelización del escurrimiento superficial.

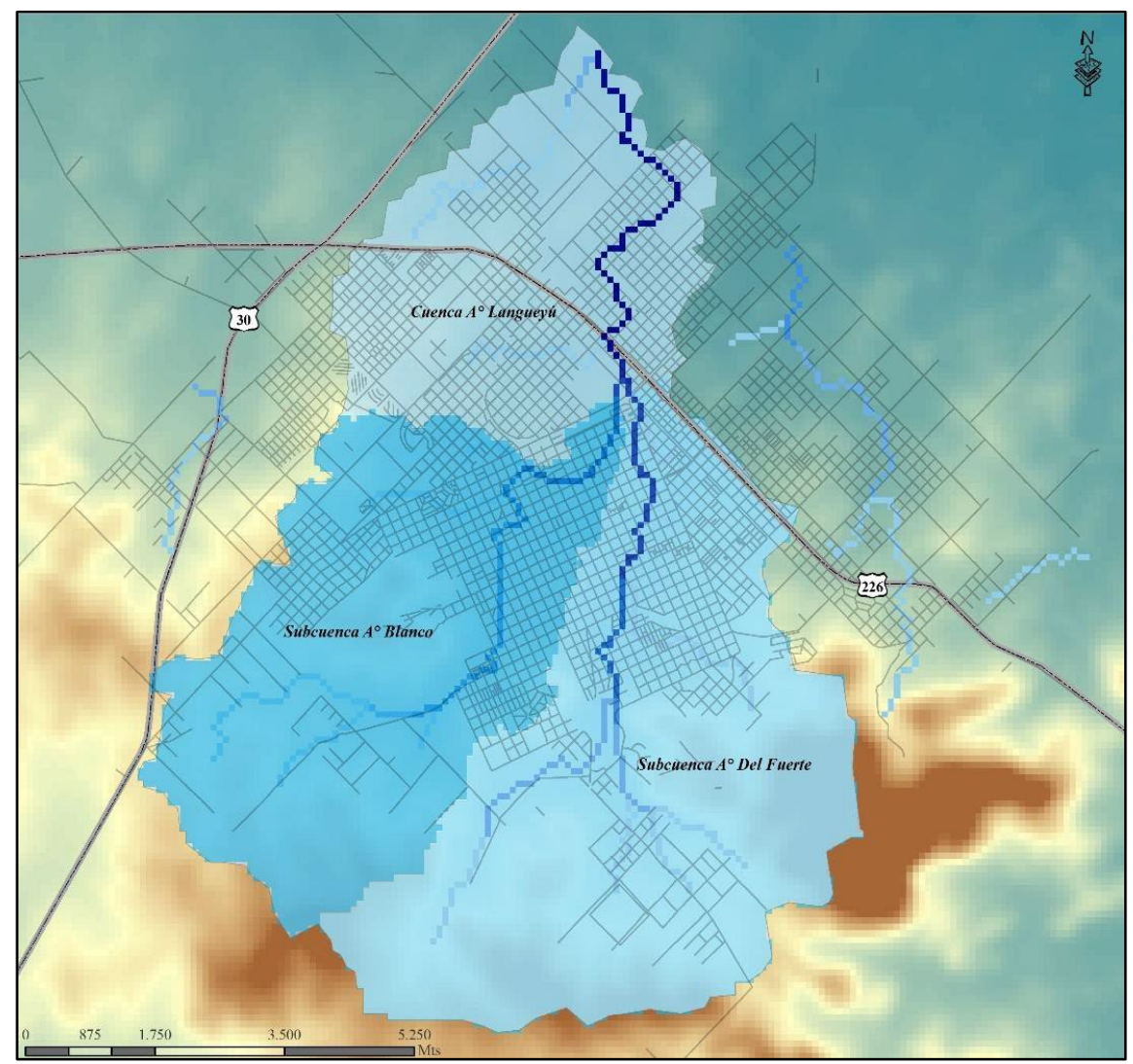

Figura 5. Cuenca urbana Langeyú. Ciudad de Tandil Fuente: La Macchia, 2015.

3) Cuenca urbana de la ciudad de Tandil y su red de infraestructura pluvial, Figura 5 y Figura 6. En primer lugar, se llevó a cabo la extracción de algunos parámetros morfométricos derivados del estudio del MDE y, en segundo lugar, se realizó la digitalización y edición de la red de infraestructura pluvial del área urbana (La Macchia, 2015). Para ello, para el primer caso, se utilizó el módulo de hidrología de ArcGIS y, para el segundo caso, las fuentes partieron de la planimetría disponible en 
formato analógico de la Dirección de Hidráulica de la provincia de Buenos Aires. Se discriminaron los conductos principales y ramales de los arroyos Blanco y Del Fuerte. Cada arco o segmento de la red, entubamiento y ramales, tiene definido un conjunto de atributos y variables referidos a sus características estructurales, espaciales y topológicas. Se constató y avanzó en la carga de información proveniente de los perfiles longitudinales de cada tramo o sección completando atributos que podrán utilizarse en futuros trabajos como pesos y restricciones al escurrimiento en zonas testigo obtenidas del mapa de peligro de anegamiento en La Macchia, 2015. Los nodos definidos por las alcantarillas y/o cámaras de inspección, suponen la conexión entre arcos y contienen información respecto al sentido y tipo de dirección que siguen los recursos gestionados por la red.

Finalmente, una vez generados los insumos básicos, el proceso siguiente consistió en la ejecución de la simulación, que en sí mismo implicó tres etapas:

1) PREPROCESO, trabajo previo de integración de inputs mediante ArcGIS y HEC-GeoRAS, para generar un archivo de importación para HEC-RAS que va a contener la información geométrica de las secciones transversales.

2) MODELIZACIÓN, consiste en la modelización del flujo del escurrimiento en HEC-RAS y generación de los archivos de exportación para procesarlos en ArcGIS.

3) POSPROCESO, nuevamente en ArCGIS y HEC-RAS, en donde se analizan los resultados de la modelización, detectando áreas con peligro a inundación con base en mapas de profundidad y velocidad, metodología extraída de la guía AEMI 2013 que establece una escala de peligro cuantificando el riesgo vinculando los resultados obtenidos del producto de las variables depth y velocity.

Siguiendo la metodología propuesta anteriormente, la primera etapa consistió en integrar los inputs que conformarán el modelo hidrológico e hidráulico, esto incluye, ingresar el MDT mediante la herramienta RAS Mapper; la geometría con los elementos que componen la red, mediante la herramienta Hec-GeoRAS para ArcGIS y la asignación de los coeficientes de rugosidades (mannings) a la red a partir de los valores de la evolución de la superficie edificada para los años 1996 y 2011. 

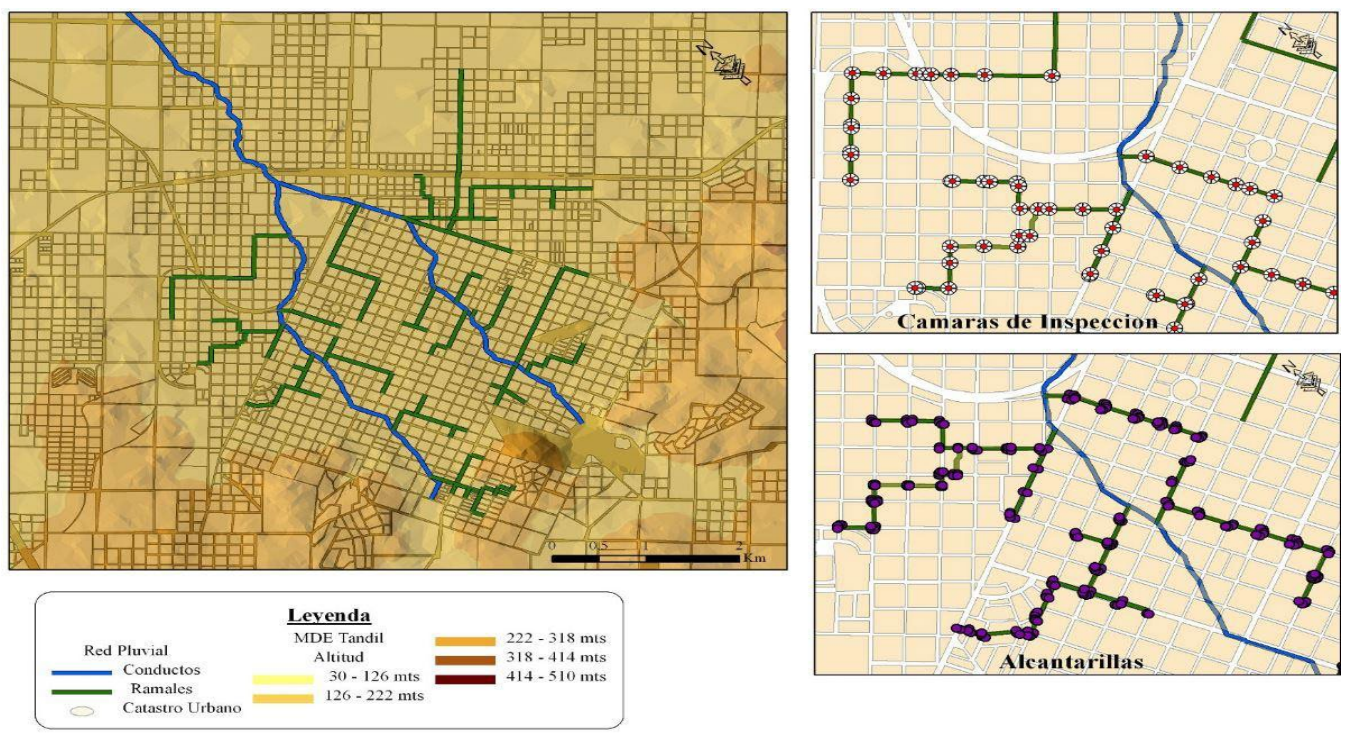

Figura 6. Red de infraestructura pluvial de la cuenca urbana de la ciudad de Tandil Fuente: La Macchia, 2015.

Posteriormente, se integró la red y la cuenca, Figura 7 a, b y c. A tales fines se emplea la herramienta RAS Mapper para el ingreso de los usos de suelo (a) y la asignación de coeficientes de rugosidad (mannings) según las clases establecidas de menor a mayor costo de escurrimiento, dependiendo del material de cubierta del terreno, de menos edificado a más edificado en este caso (b), en nuestro ejemplo se asignaron diferentes mannings para seleccionar los más indicados que reflejen la realidad. En ese caso se recurrió a revisar los parámetros estándares de coeficientes que se manejan según cada tipología de uso (HEC-RAS, 2016a y HEC-RAS, 2016b). En este sentido, según la topografía del terreno, su geomorfología y pendiente se determinaron para el Uso 1: 0.03, Uso 2: 0.05 , Uso 3: 0.084 y Uso 4: 0.152. Finalmente, se asoció la geometría a los usos (c). 
Fig 7 (a)

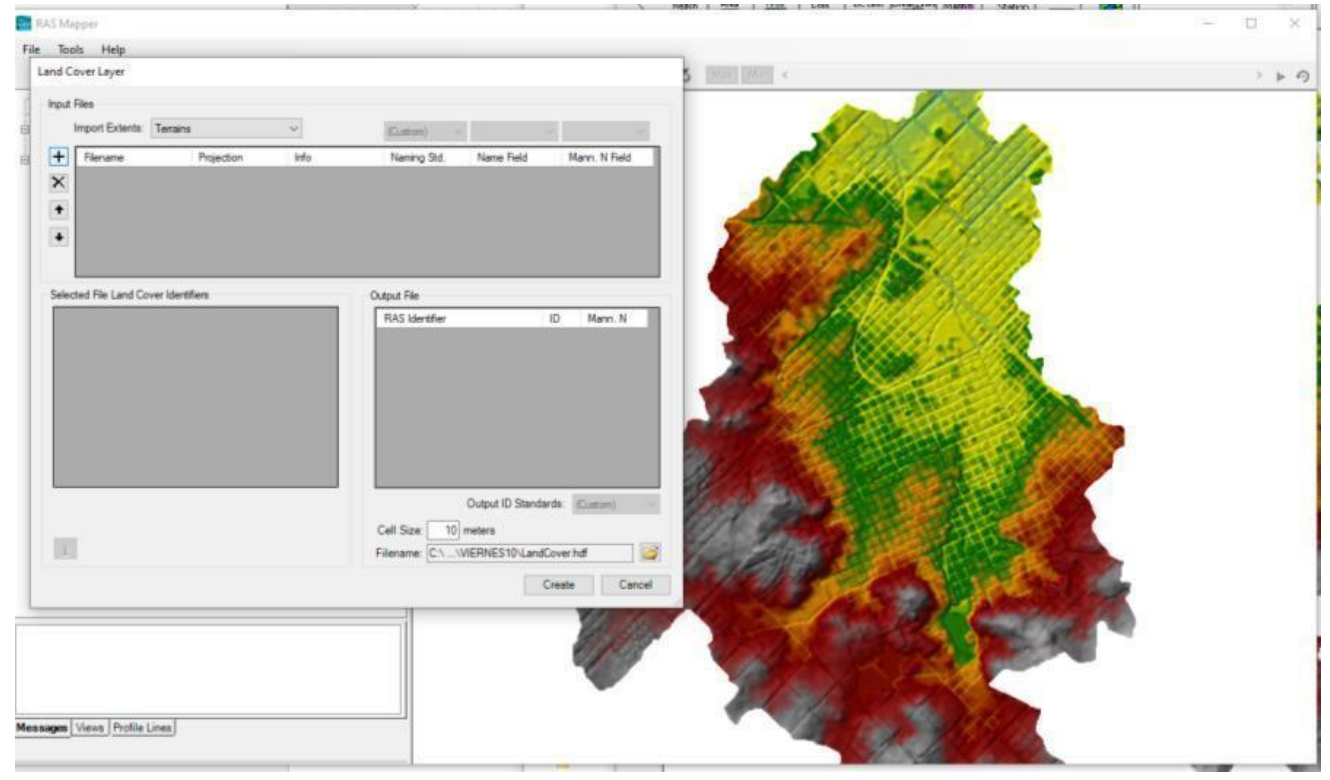

Fig 7 (b)

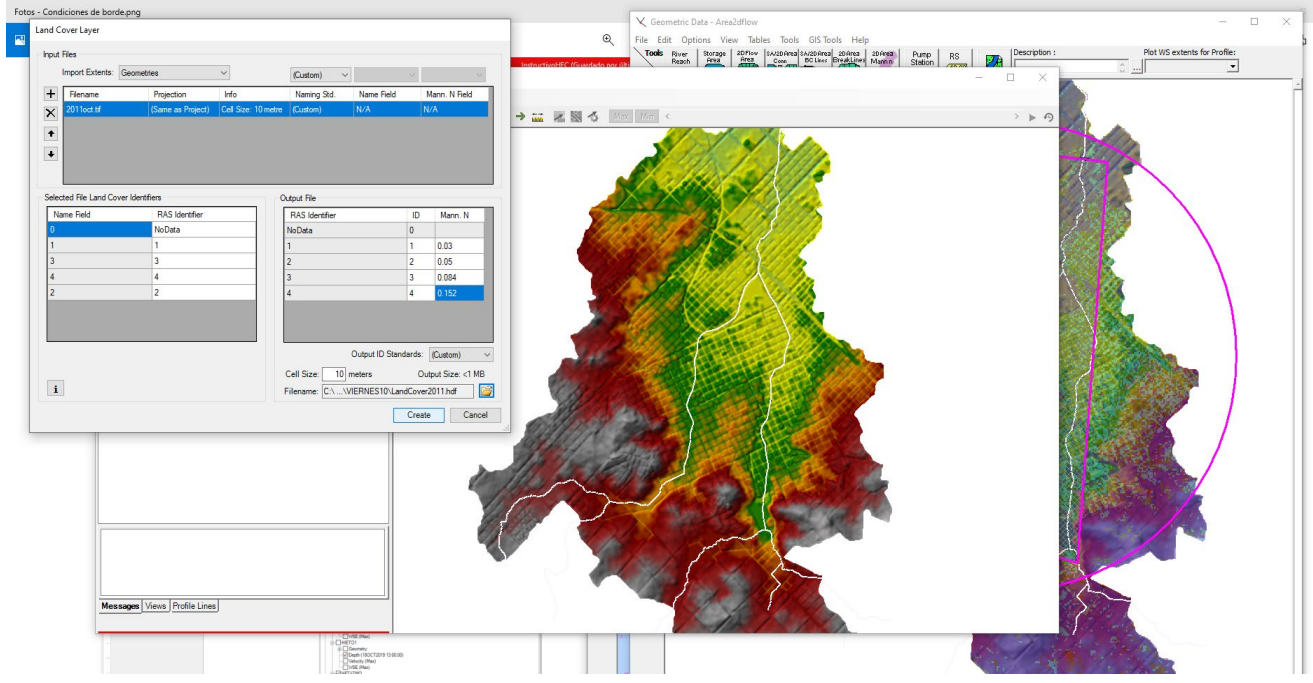

CC BY-NC 4.0 | BOLETín DE ESTUDIOS GEOGRÁFICOS 115 | ISSN 0374-6186 | ISSN: 2525-1813 (DIGITAL) | 81 
Fig 7 (c)

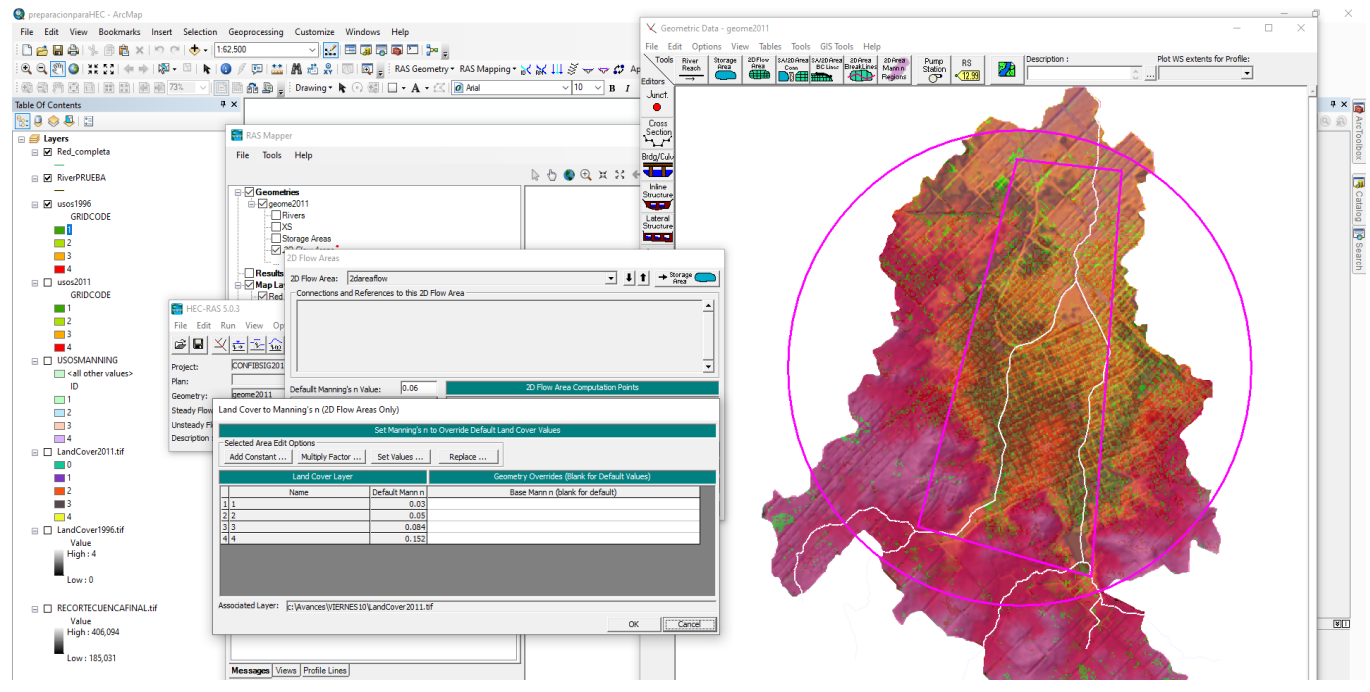

Figura 7. Integración de red y cuenca en HEC-RAS

Fuente: Elaboración personal en base a procesamiento con HEC-RAS 5.0.3.

Fig 8 a)

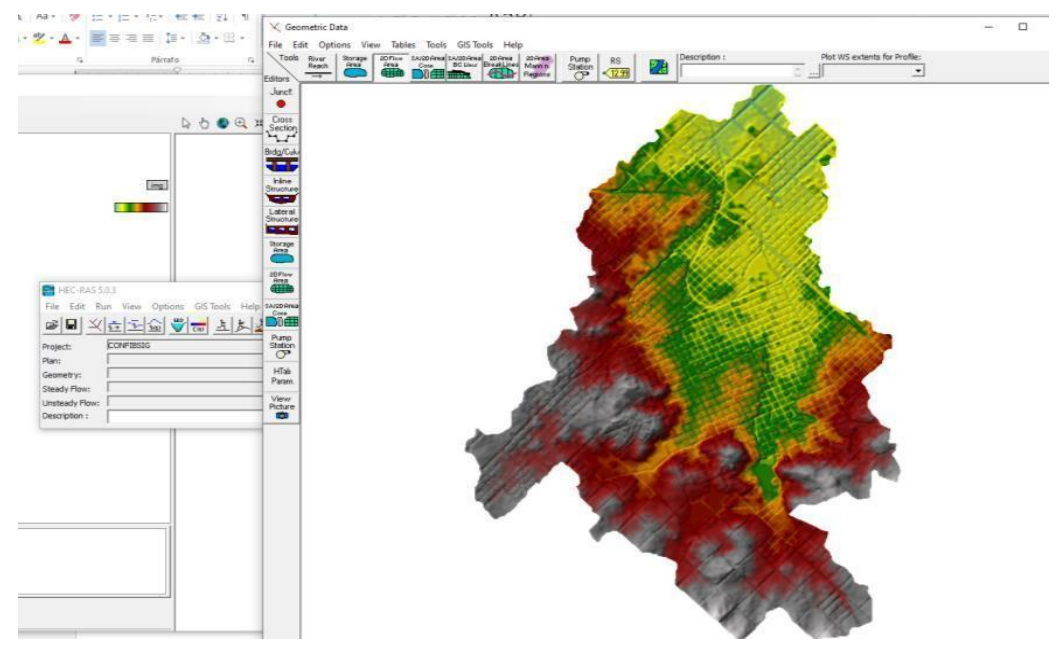

82 | CC BY-NC 4.0 | BOLETín DE ESTUDIOS GEOGRÁFICOS 115 | ISSN 0374-6186 | ISSN: 2525-1813 (DIGITAL) 


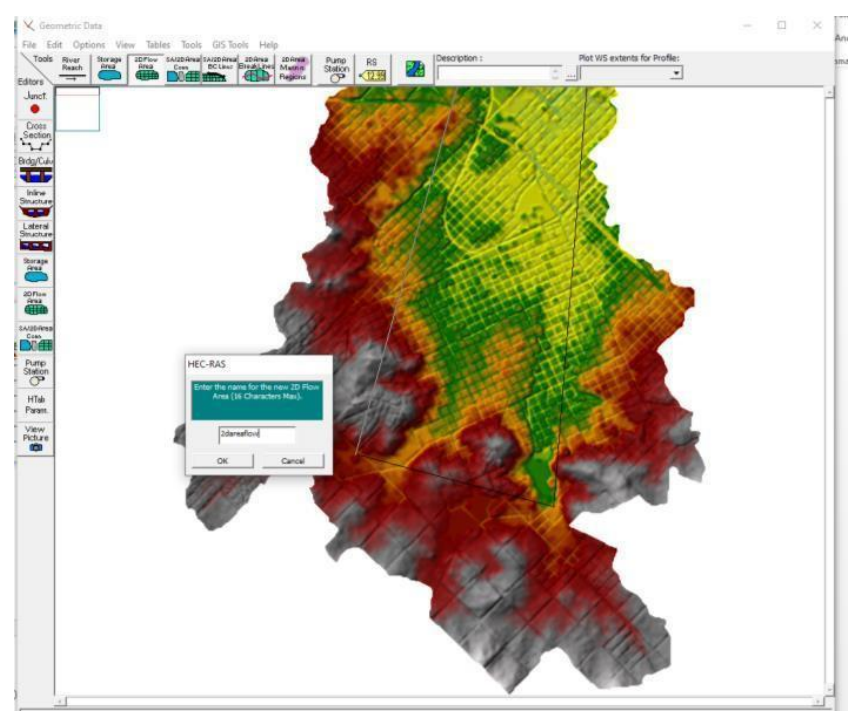

Fig 8 b)

La opción default manning values permite identificar el mapa de coberturas (landcover) con sus respectivos coeficientes de rugosidad (mannings) asignados.

Definida la malla es requisito establecer las condiciones de contorno (2DFLOWConditionboundary), en donde se asignan las fuentes (sources/entradas) y los sumideros (sinks/salidas). Para la simulación se definieron los IN y OUT, figura 9, indicando dos fuentes, en el arroyo Blanco y el arroyo Del Fuerte y un sumidero, en el Arroyo Langueyú. 


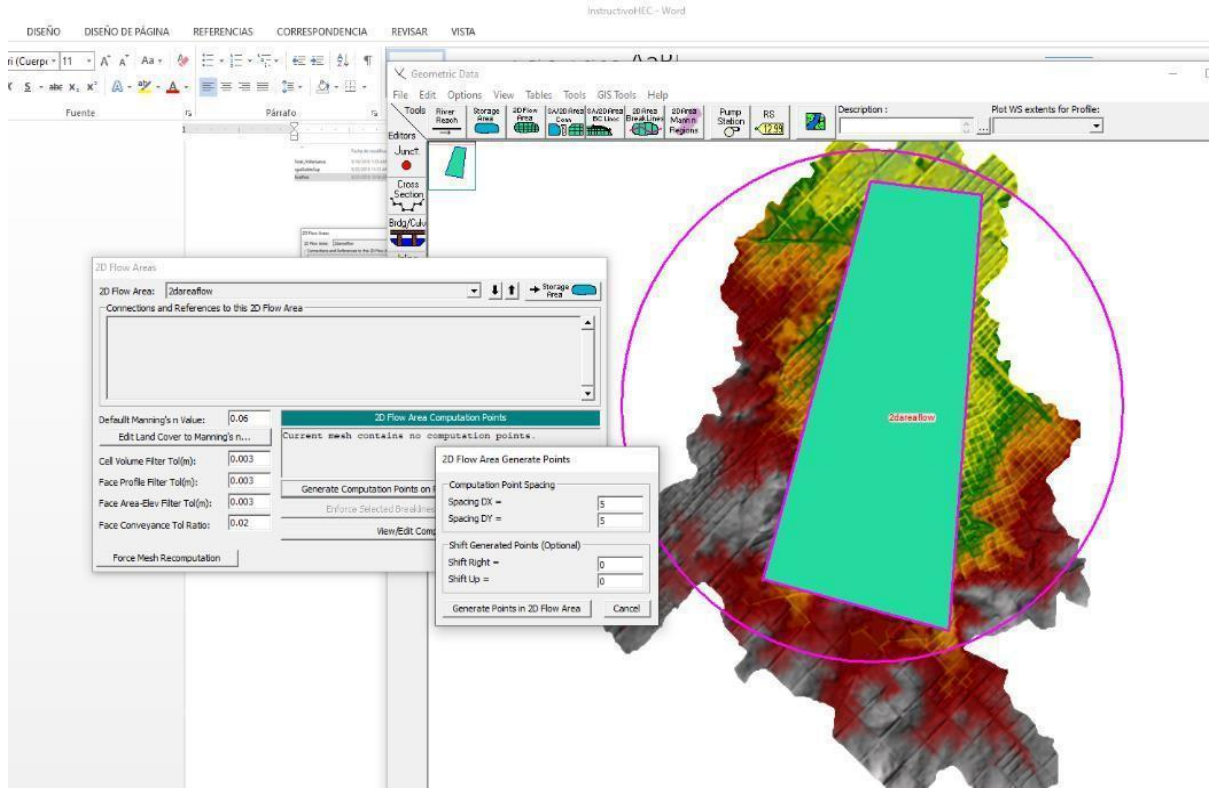

Figura 8. Construcción del dominio de la cuenca

Fuente: Elaboración personal en base a procesamiento con HEC-RAS 5.0.3.

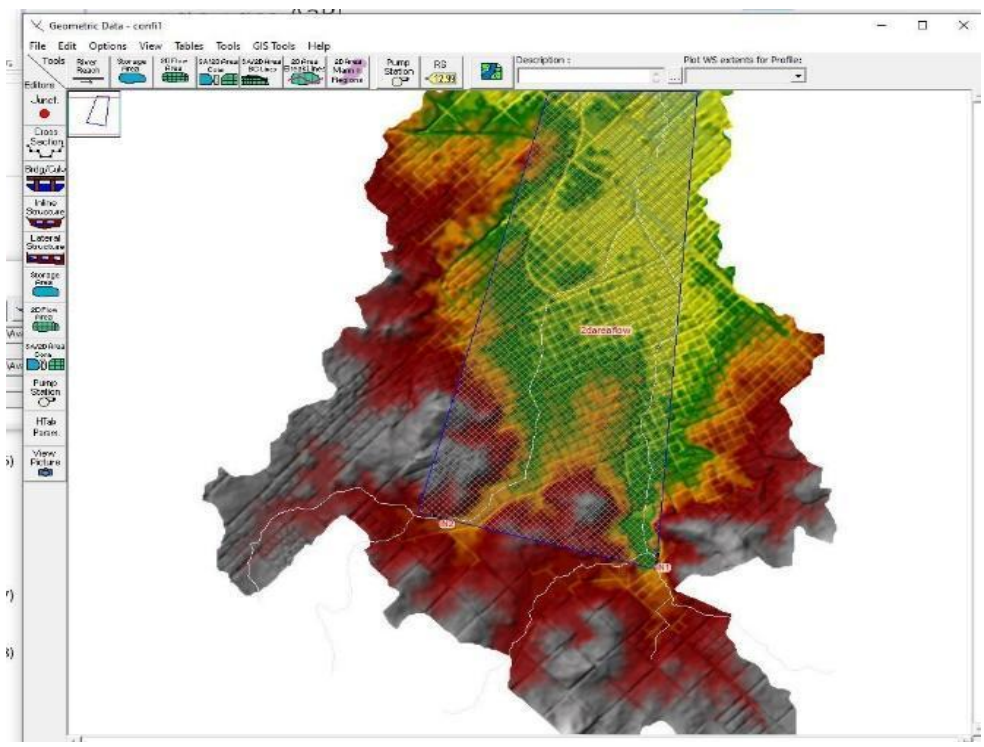

84 | CC BY-NC 4.0 | BOLETín DE ESTUdIOS GEOGRÁFICOS 115 | ISSN 0374-6186 | ISSN: 2525-1813 (DIGITAL) 


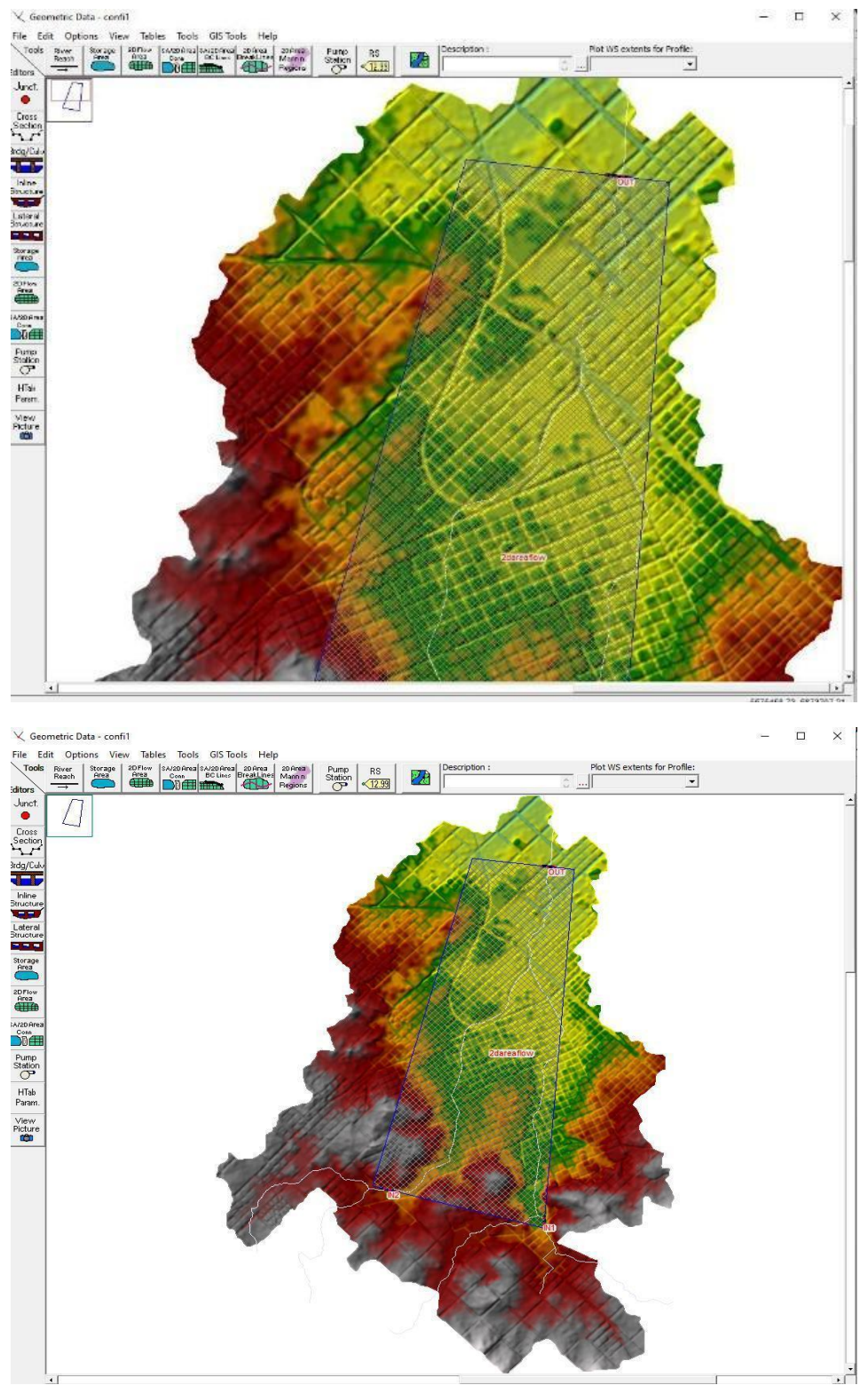

Figura 9. Definición de las condiciones de contorno del mallado Fuente: Elaboración personal en base a procesamiento con HEC-RAS 5.0.3. 
Delimitados los ingresos y egresos, mediante HEC-RAS se introdujeron los caudales estables o inestables. La opción Steadyflowdata aplica para un caudal permanente o constante, mientras que Unsteadyflowdata refiere a un caudal variable según la intensidad de la lluvia en fracciones de tiempo (duración). Para la simulación ingresamos los datos en Unsteadyflowdata, Figura 10.

Esta instancia requirió de la confección de un hietograma o un hidrograma para simular las precipitaciones según los parámetros establecidos previamente. La opción adoptada fue la del hidrograma a partir del cual es posible observar la evolución de la lámina de agua en el tiempo, Figura 11 y Figura 12. A nivel de sección, esta definición permitió conocer cómo sube la lámina de agua llegando a su punto máximo y como va bajando conforme pasa el tiempo. En el presente trabajo se ensayaron distintos escenarios con base en hidrogramas de lluvias en $\mathrm{mm}$ obtenidos mediante la toma de datos por la estación meteorológica NET ATMO (datos $\mathrm{x}$ horas del 17/10 al 18/10 del año 2019)3. Pero para obtener resultados más evidentes se decidió trabajar un escenario con hidrogramas de caudales en $\mathrm{m} 3 / \mathrm{seg}$.

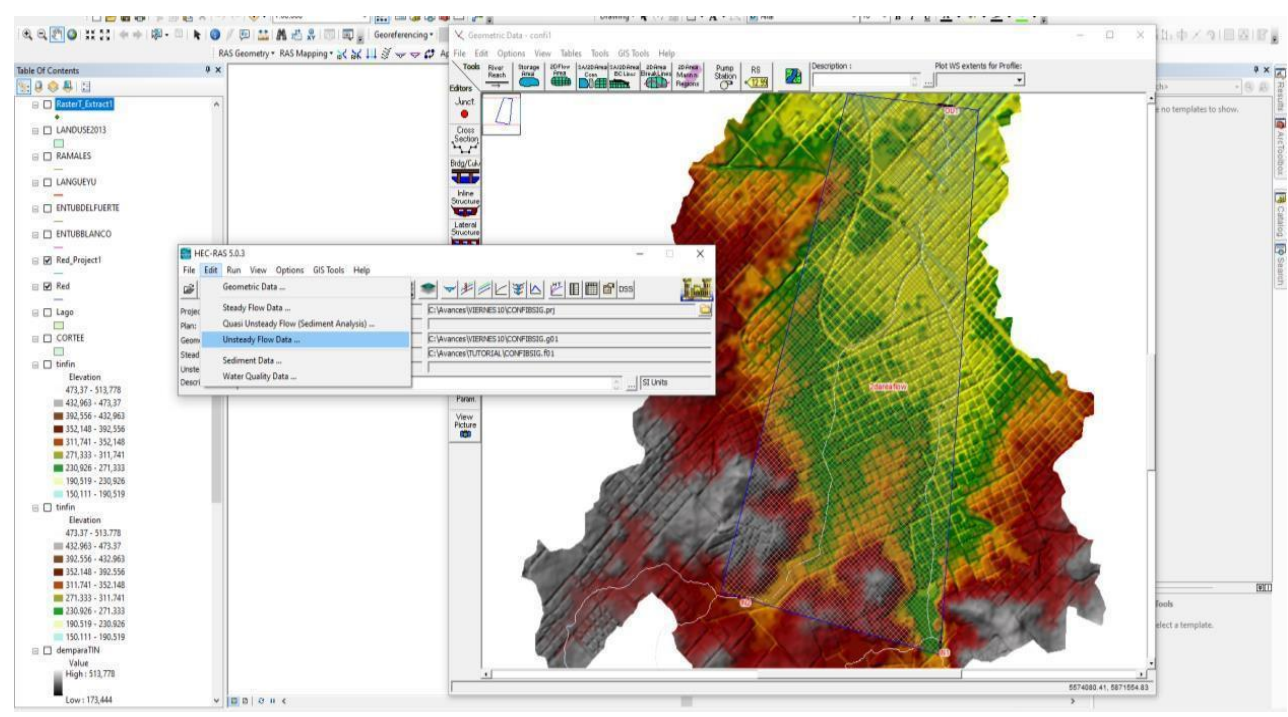

Figura 10. Introducción de caudales mediante HEC-RAS

Fuente: Elaboración personal en base a procesamiento con HEC-RAS 5.0.3.

\footnotetext{
${ }^{3}$ Disponible en: https://www.netatmo.com/es-es/weather/weatherstation
} 
Flow Hydrograph

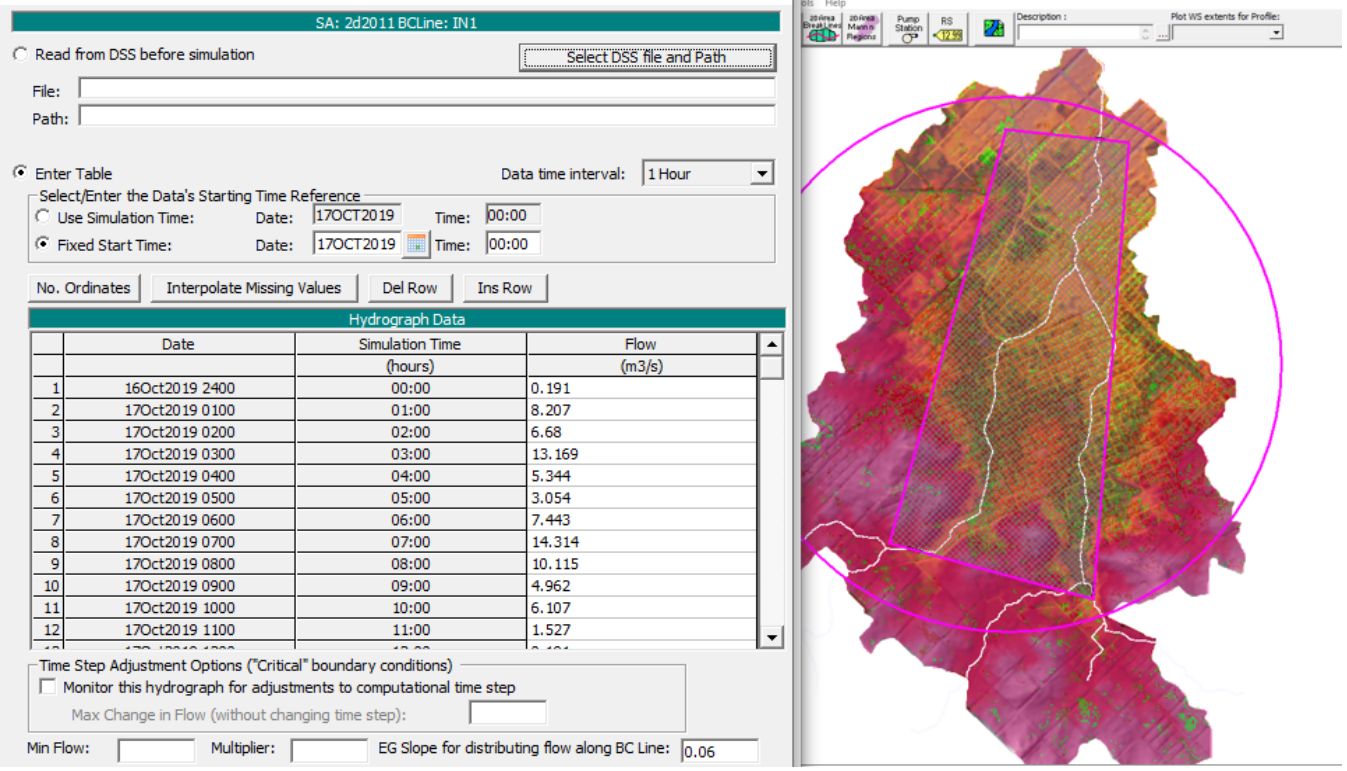

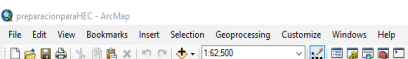

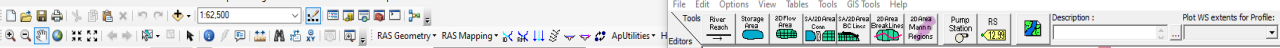

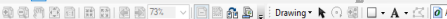

Toble 아 Contents

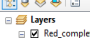

G $\mathrm{T}$ Riveprueba

日) usos 1996

จ1 USOS1996
GRIDCODE

Gil

$\square_{2}^{2}$
$\square^{3}$
$\square_{4}^{4}$
45052011

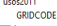

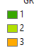

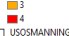

$\square$ <all ther values

10

$\square 1$

$\square^{3}$

LandCover2011.tif

믄 1

물

$\square$ Landcover 1998

Value
High:
tom:

$\square$ RECORTECUENCAFNQLLIf

Value
High: 406,004

File Edit Run View Options Gistools Hép

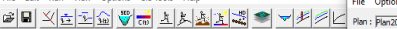

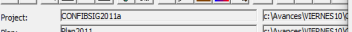

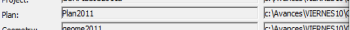

Geomedy: beame 011

Unsteady Flow: Freborat 2011
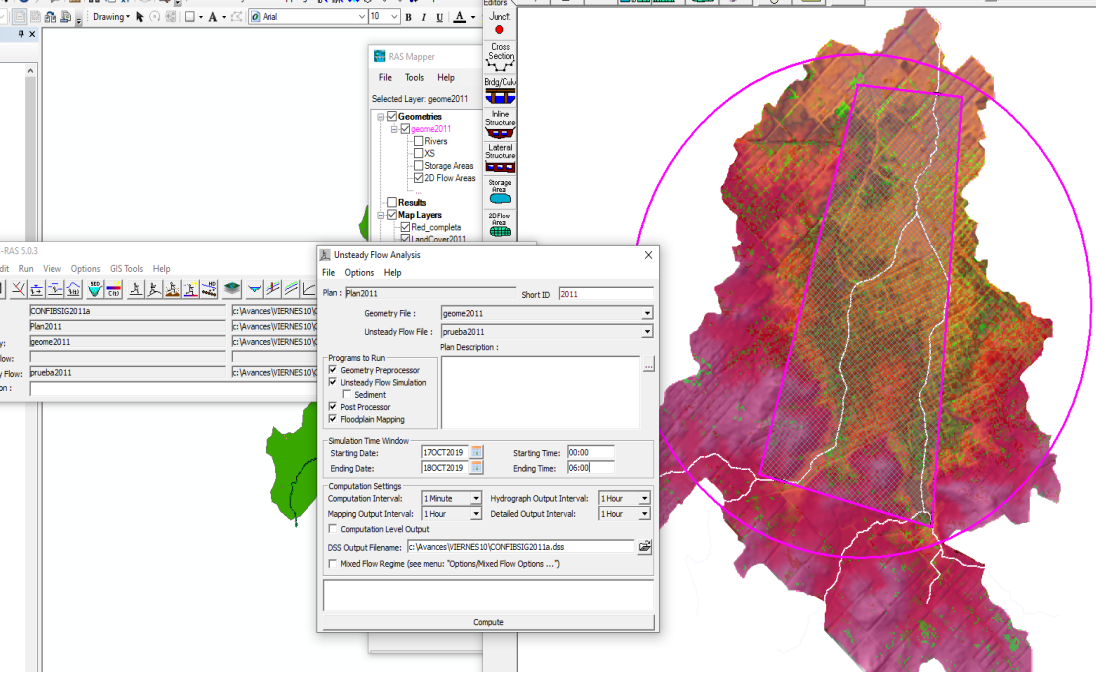

Figura 11. Introducción de hidrograma mediante HEC-RAS

Fuente: Elaboración personal en base a procesamiento con HEC-RAS 5.0.3.

CC BY-NC 4.0 | BOLETín DE ESTUDIOS GEOGRÁFICOS 115 | ISSN 0374-6186 | ISSN: 2525-1813 (DIGITAL) | 87 


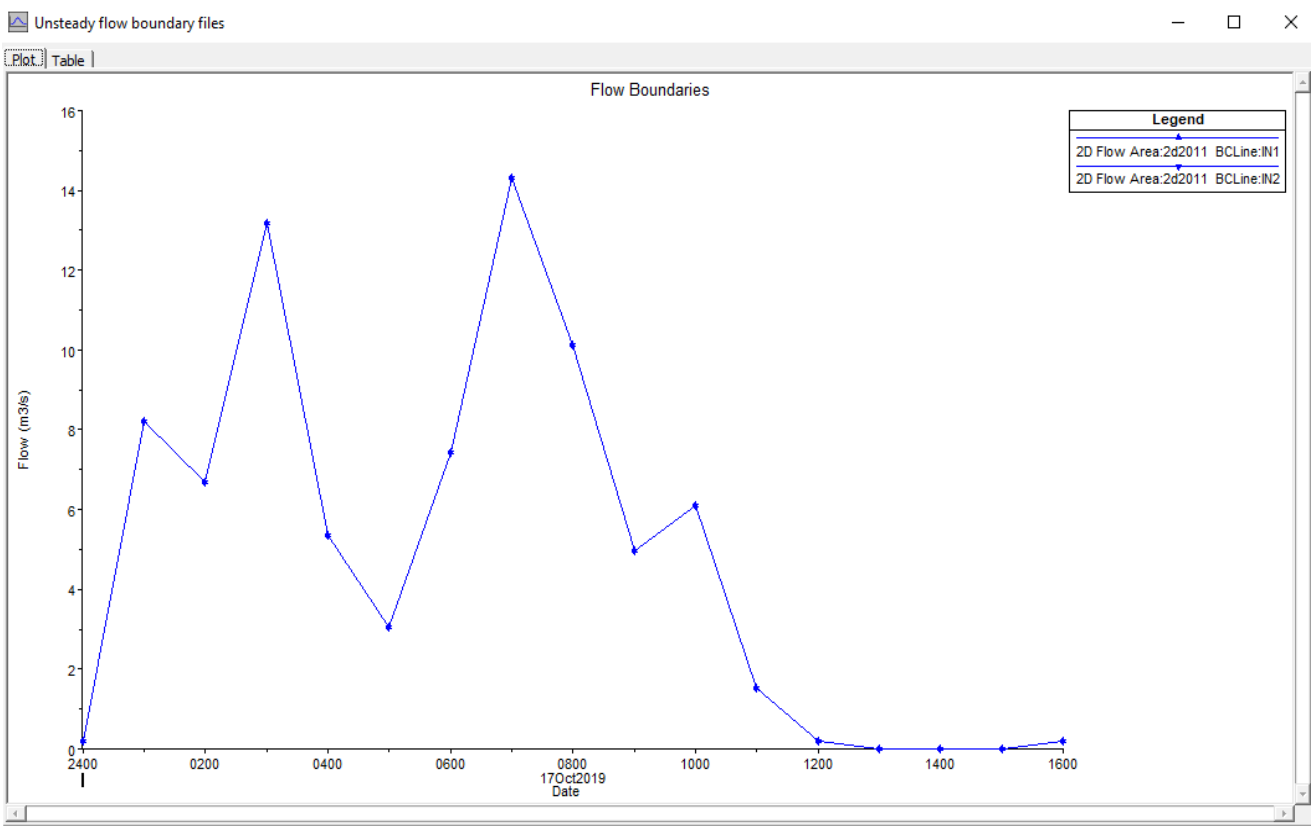

Figura 12. Vista en plot del hidrograma del evento en HEC-RAS Fuente: Elaboración personal en base a procesamiento con HEC-RAS 5.0.3

\section{RESULTADOS}

La etapa de pos procesamiento mediante la simulación de los escenarios se presenta en RAS Mapper. En esta ventana se visualizan los resultados tanto por: perfiles, hora, tiempo determinado, profundidad y velocidad máxima, entre las representaciones más destacadas. El rango global de valores con respecto a la profundidad del agua, Figuras 13 y 14 no varía durante el período, alcanzando un umbral de 5.02 metros en 1996 y 2011 . Sin embargo, se observa un incremento de celdas en el rango de 1.9 metros en detrimento del rango de 1.2 metros. El hallazgo más importante se encuentra al realizar un análisis de distribución espacial de las diferencias entre ambos momentos, Figura 15 donde se presentan cuáles han sido las celdas que han arrojado variación positiva y negativa con respecto a la profundidad del agua acumulada entre las simulaciones 1996-2011, en el mapa se observa que un $70 \%$ de las celdas en el área simulada incrementa la profundidad del agua retenida, 
exhibiendo aumentos hasta de 1.2 metros en algunos puntos, corroborando la clara asociación entre aumento de la densidad de superficie edificada y retención del agua ante eventos extremos, lo cual genera ineludiblemente un mayor peligro a inundaciones. Esta primera parte del análisis se complementa a su vez con los resultados siguientes, Figuras 16, 17 y 18, en los cuales, se detecta un leve incremento de las celdas en el rango $0.1 \mathrm{~m} / \mathrm{s}$ en detrimento de una disminución del rango $0.05 \mathrm{~m} / \mathrm{s}$. Asimismo, un $58 \%$ de las celdas incrementan la velocidad de escurrimiento $(\mathrm{m} / \mathrm{s})$ producto de la impermeabilización de la superficie que genera el aumento de las construcciones.
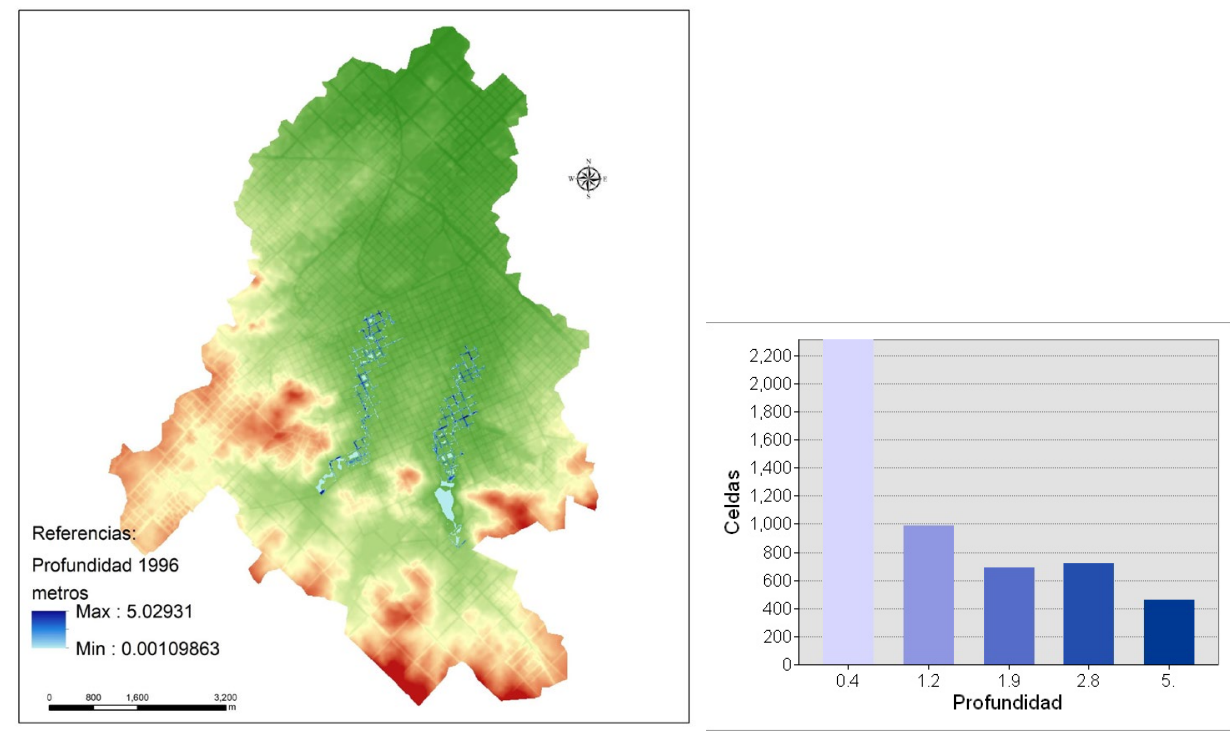

Figura 13. Escenario profundidad simulada 1996 Fuente: Elaboración personal. ArcGIS 10.2. 

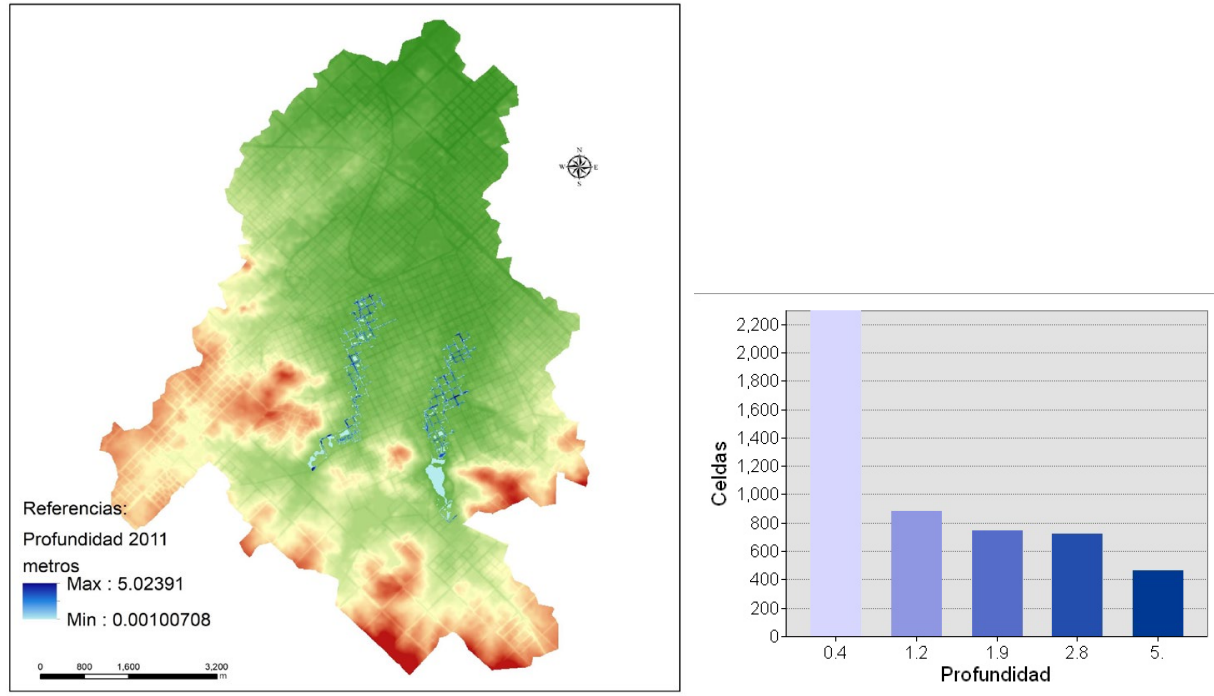

Figura 14. Escenario profundidad simulada 2011 Fuente: Elaboración personal. ArcGIS 10.2. 


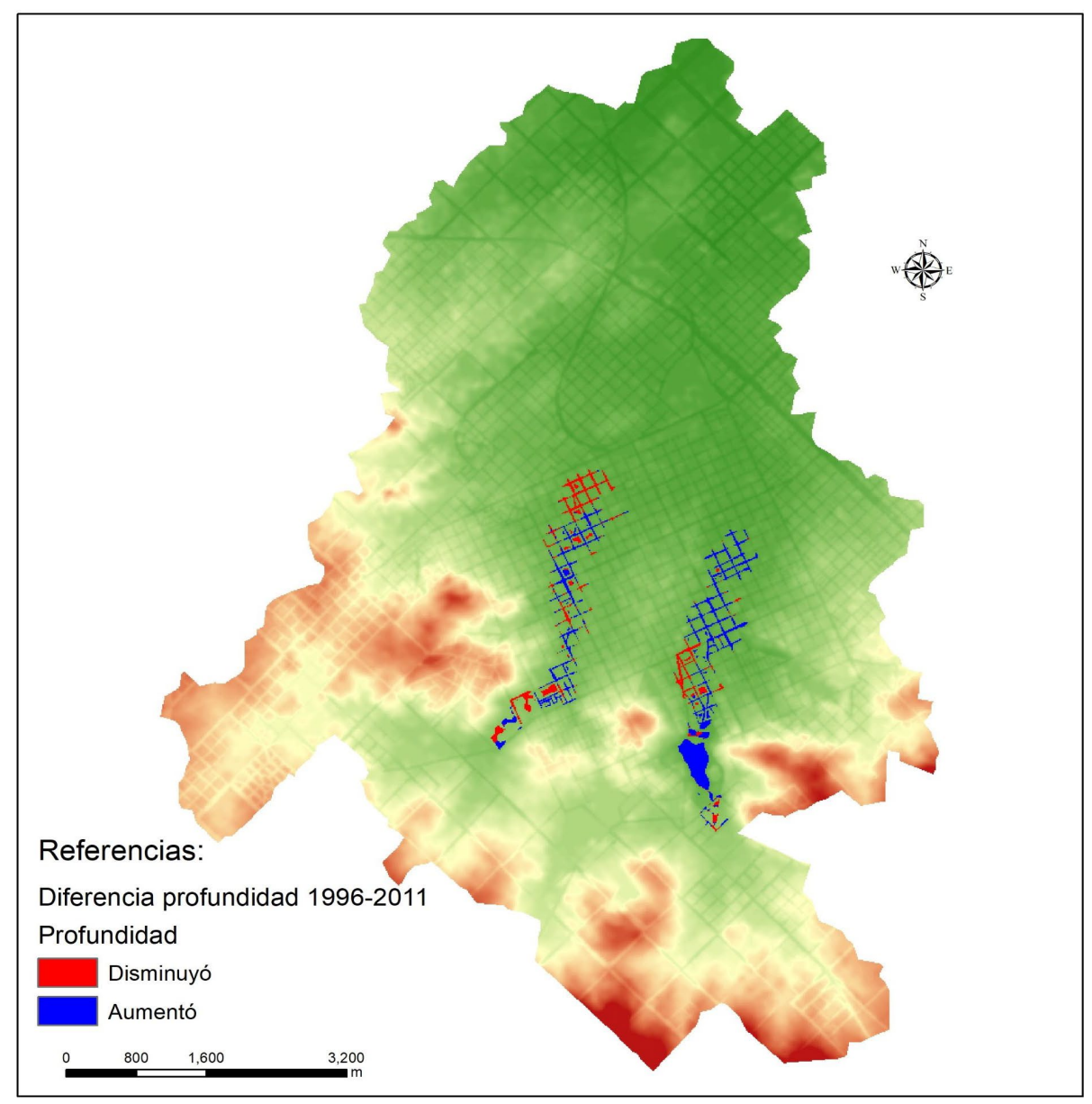

Figura 15. Diferencias profundidad simulada 1996-2011 Fuente: Elaboración personal. ArcGIS 10.2 

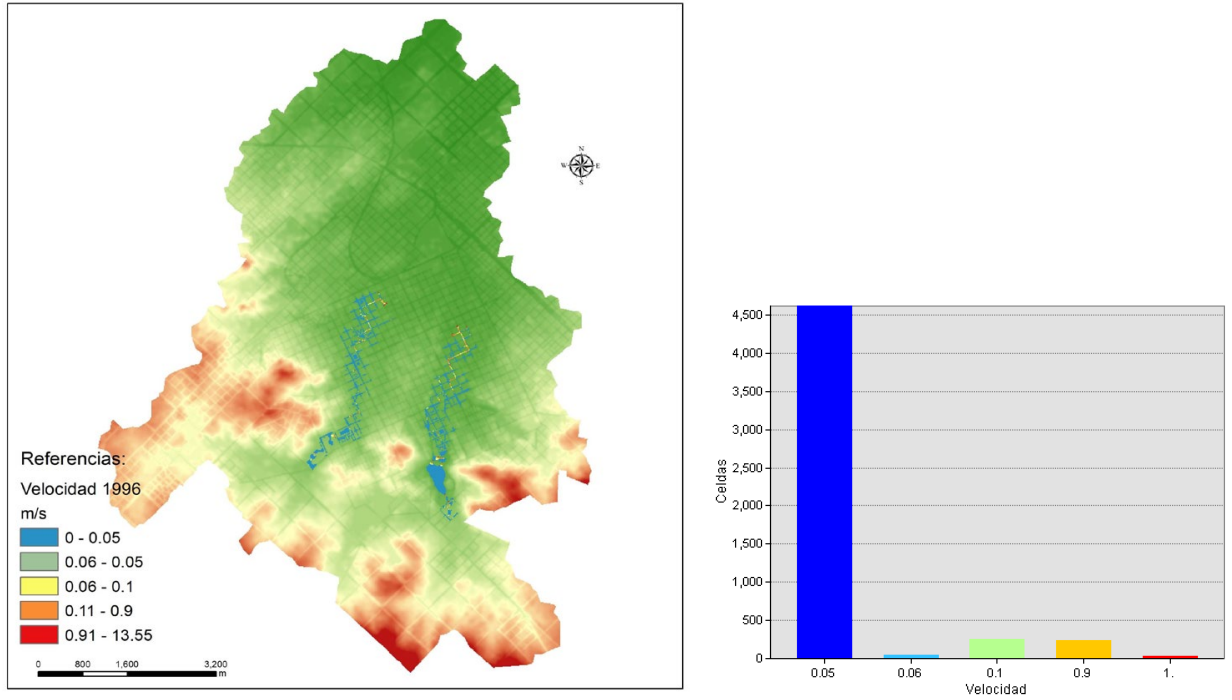

Figura 16. Escenario velocidad simulada 1996 Fuente: Elaboración personal. ArcGIS 10.2.
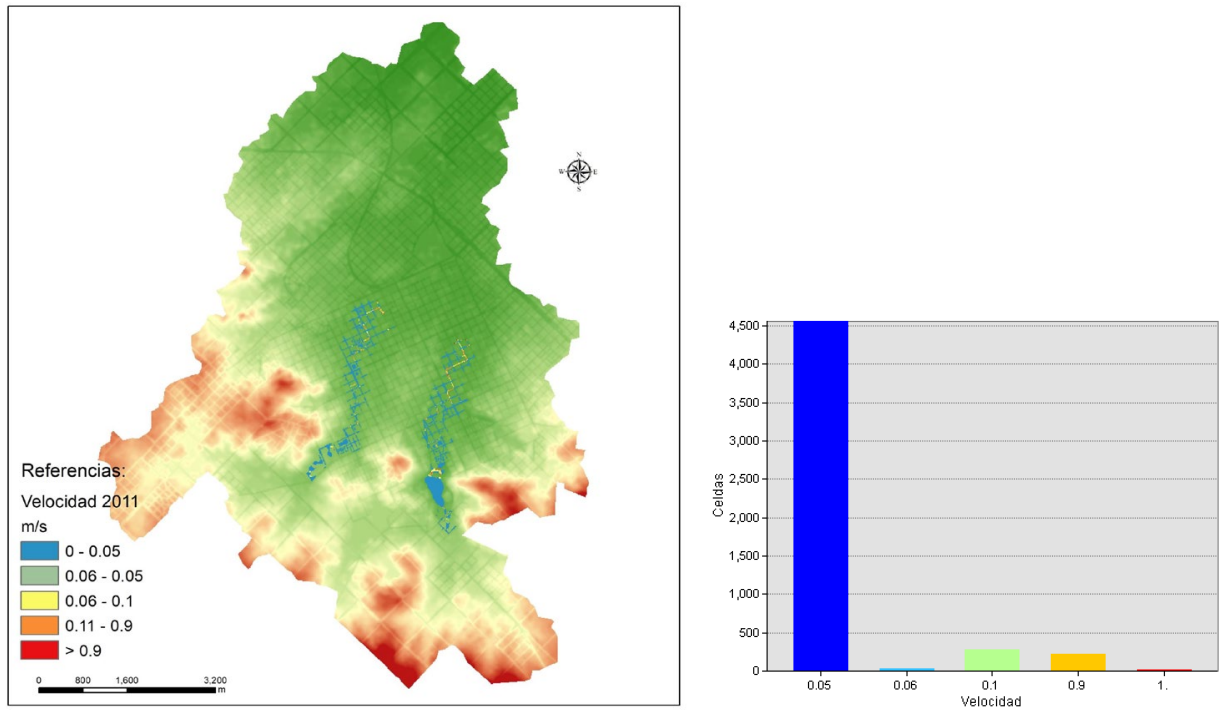

Figura 17. Escenario velocidad simulada 2011 Fuente: Elaboración personal. ArcGIS 10.2. 


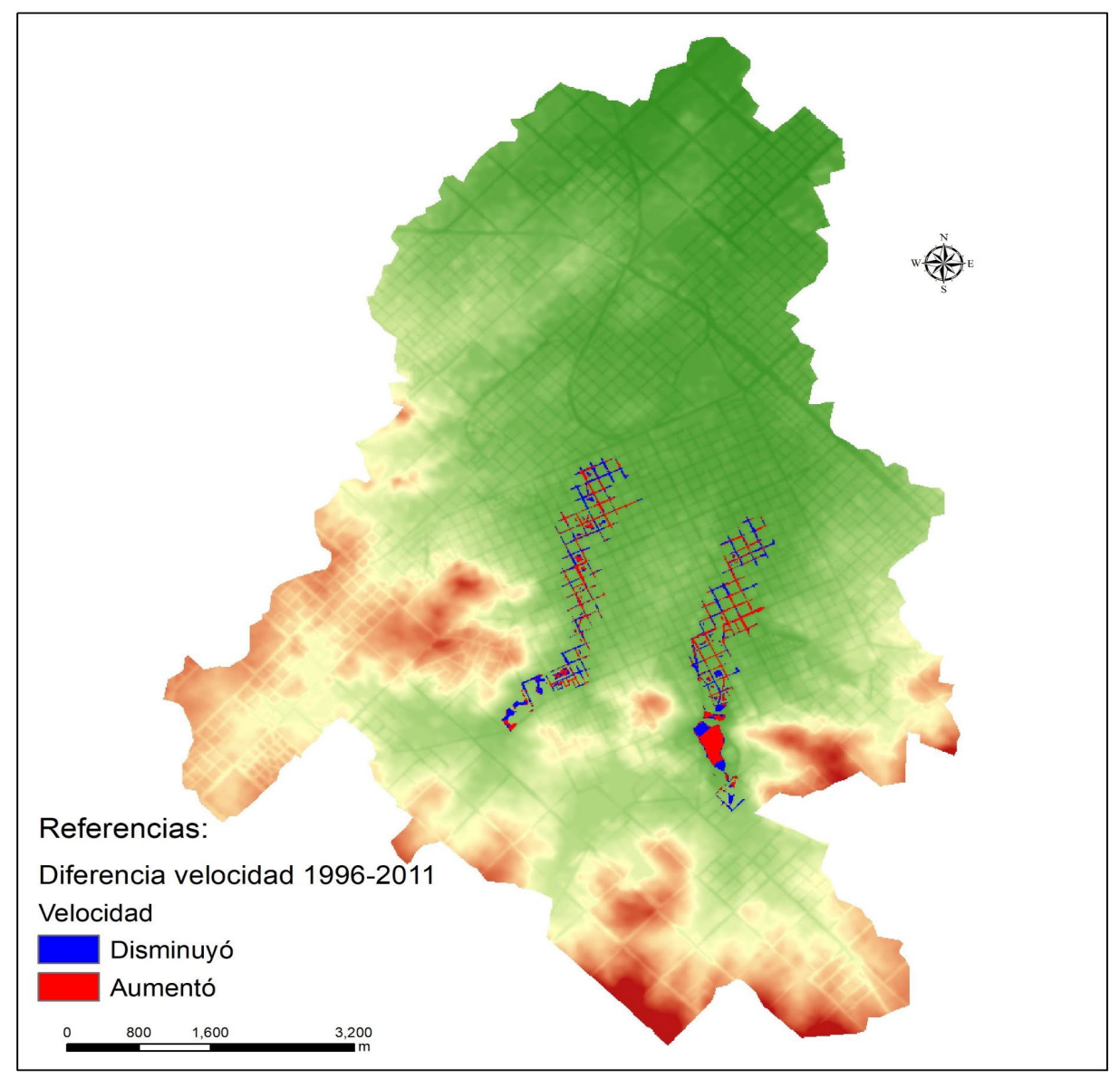

Figura 18. Diferencias velocidad simulada 1996-2011 Fuente: Elaboración personal. ArcGIS 10.2.

A partir de los productos cartográficos obtenidos fue posible definir un mapa de áreas de peligro a inundaciones, las cuales resultan de suma utilidad práctica para la toma de decisiones territoriales y se construyen a partir de una combinación de la profundidad por la velocidad (AIDR, 2014 y AEMI, 2013). En este sentido, el peligro es mayor a medida que aumenta la profundidad y la velocidad, profundizándose la 
situación por la combinación entre ambas variables. En este trabajo se realizó una adaptación local del método elaborado por el Instituto Australiano de Resiliencia ante Desastres, partiendo de una operación de multiplicación entre las capas ráster de profundidad y velocidad, cuyo ráster resultante permitió definir cuatro rangos con niveles de peligrosidad creciente que se establecieron de la siguiente manera: nulo, bajo, medio-bajo y medio, Figura 19:

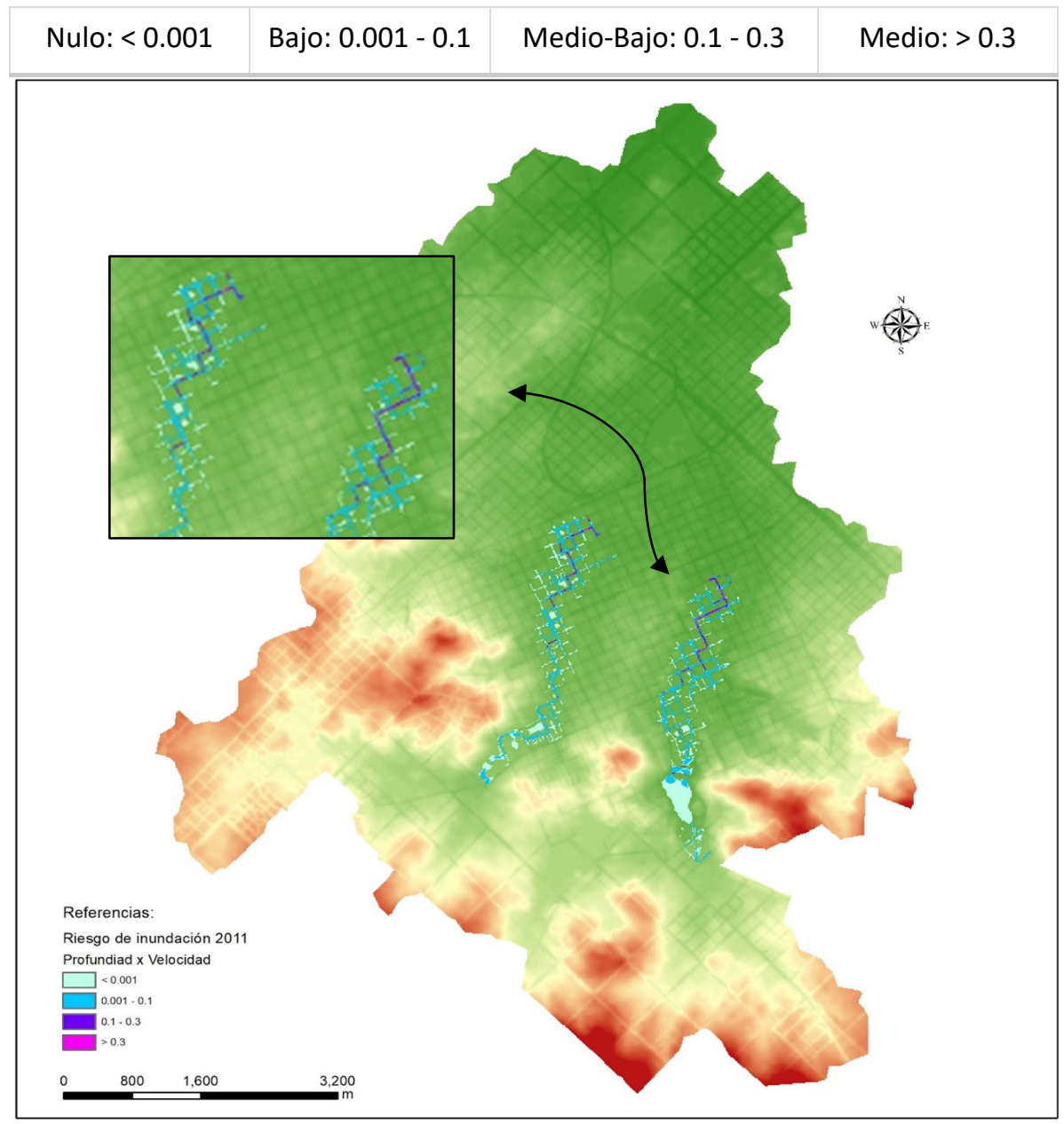

Figura 19. Riesgo de inundación 2011

Fuente: Elaboración personal. ArcGIS 10.2. 
La figura 18 permite identificar cuatro áreas según niveles de riesgo mediante un indicador sintético, como sustento para generar medidas de gestión urbanísticas estructurales o semiestructurales ante eventos extremos. La interpretación de los niveles de peligro indicados, expresan potenciales niveles de vulnerabilidad de las personas que caminan o conducen a través del área de estudio durante un evento extremo. El presente resultado se expone como un recorte preliminar a modo de corroboración metodológica y utilidad práctica, a partir del cual se pretende profundizar en un estudio sobre el manejo integral en toda el área urbana y complementaria de la ciudad de Tandil que se encuentra en desarrollo.

\section{DISCUSIÓN Y CONCLUSIÓN}

Se destaca la posibilidad de integrar satisfactoriamente diversas fuentes y modelos de geodatos para la simulación de escurrimiento superficial, imágenes de sensores ópticos y radar, capas vectoriales de fuentes primarias y secundarias como elementos básicos que configuran el espacio urbano y componentes geométricos propio del análisis de redes integrados dentro del modelo hidrológico. También la capacidad de asignar atributos que relacionen, conecten e integren cada uno de estos elementos de la trama urbana con el modelado final del escurrimiento.

La capacidad de vincular una variedad de herramientas geotecnológicas garantizó la correcta interoperabilidad entre los insumos básicos y resultados durante cada fase del procedimiento metodológico sugerido. Todo ello hizo posible corroborar la hipótesis de trabajo, a partir de la cual pronosticamos el impacto que tiene el aumento de densidad de edificaciones sobre el riesgo de áreas urbanas a inundarse. La determinación de zonas de peligro en base a la clasificación que propone AEMI 2013 es un antecedente importante desde la Geografía Aplicada intentando detectar zonas de mayor y menor vulnerabilidad conjugando el producto de los escenarios de los mapas de profundidad (depth) y velocidad (velocity). El análisis para cuantificar de manera precisa el riesgo requiere tener más variables en consideración y mayor precisión en los resultados, ya que las curvas de vulnerabilidad se establecen en base a los umbrales establecidos (número de píxeles) para cada categoría utilizada en los mapas obtenidos. 
Este aporte constituye una nueva evidencia que contrarresta el poder de la naturaleza como el único agente de los desastres, si bien los factores físicos pueden ser poderosos detonadores de acontecimientos, los procesos conductuales reales son los sociales, es la naturaleza de esos procesos sociales los que determinan qué ocurrirá, dónde y con qué intensidad se materializará en el territorio.

No obstante, varios aspectos de nuestro procedimiento metodológico son optimizables, comenzando por la reducción de la exageración de la escala vertical en el Modelo Digital de Terreno, cuya elección de elevar cinco metros por encima del MDE a aquellos polígonos que componen el catastro urbano, resulta un artificio distorsionando las interpretaciones de los valores físicos de profundidad y velocidad en los escenarios. Si bien se reconoce la debilidad en la fiabilidad de la precisión de los modelos digitales del terreno $(12,5 \mathrm{~m})$, se continúa trabajando en la mejora de su obtención y posterior procesamiento mediante el trabajo de campo, la vinculación con otras fuentes de información y la reconstrucción de los modelos a partir de vuelos de drones para las áreas más críticas o de mayor peligro en el área urbana. Sin duda estos aportes disminuirán la incertidumbre de los escenarios simulados y servirán para validar los resultados obtenidos.

Asimismo, en los escenarios obtenidos no se tuvo en cuenta el recorrido del agua dentro de los canales de la red pluvial, sólo el escurrimiento superficial, creemos que, al vincular la red mediante su drenaje a través de sus conductos y secciones transversales, el resultado variará significativamente al obtenido en este trabajo. Esta decisión metodológica también afectará a los coeficientes de rugosidad adoptados, los cuales deberán ser calibrados nuevamente.

Como conclusión general de esta aplicación, reforzamos que la implementación de Sistemas de Información Geográfica es una herramienta de gran utilidad en la definición de los escenarios, principalmente como base para la toma de decisiones. Dependiendo del aspecto que se desee analizar, pueden realizarse diversos tipos de mapas y escenarios, por ejemplo: mapas de amenaza, vulnerabilidad y/o mapas de riesgo, vinculando por un lado, la recurrencia de los eventos, los períodos de retorno, los daños potenciales en pérdidas materiales y el impacto en la calidad de vida de la población, como también, la evaluación de inversiones en términos de costos y 
beneficios económicos para la ejecución de obras derivadas de medidas de gestión y planificación territorial en pos de lograr ciudades más sostenibles.

\section{BIBLIOGRAFÍA}

Australian Emergency Management Institute (AEMI) (2013). Managing the floodplain: A guide to best practice in flood risk management in Australia, Australian Emergency Handbook (7), Canberra.

Australian Institute for Disaster Resilience (AIDR) (2014). Australian Disaster Resilience Guideline 7-3: Technical flood risk management guideline: Flood hazard, 2014, CC BY-NC.

Carballo, T.; Goldberg, S. (2014). Comunidad e información ambiental del riesgo. Las inundaciones y el Río Luján. Buenos Aires: Editorial Dunken.

Collazos, G.; Villanueva, I.; Briceño, N.; Cazenave, G.; Guevara, C.; y Blanco, M. (2018). Modelo bidimensional de inundación urbana de la ciudad de Azul (Argentina) con herramientas de uso libre. XXVIII Congreso Latinoamericano de Hidráulica. Buenos Aires, Argentina, septiembre de 2018.,2064-2075.

DeVantier, B. A. y Feldman, A. D. (1993). Review of GIS Applications in Hydrologic Modeling. Journal of Water Resources Planning and Management, 119, (2), Paper 3607, 246-259

Ellis, E. A.; Romero, J. A.; Hernández, I.U.; Gallo, C. A. y Alanís, J. L. (2012). Evaluación geográfica de áreas susceptibles a inundación en la cuenca del río Tuxpan, Veracruz. Avances en Investigación Agropecuaria. 2012. 16(1): 7-28.

Fernández Pato, J. y García Navarro, P. (2018). Development of a New Simulation Tool Coupling a 2D Finite Volume Overland Flow Model and a Drainage Network Model. Geosciences. 8-288.

Ferrando A. y Francisco J. (2006). Sobre inundaciones y anegamientos. Revista de Urbanismo, (15), Facultad de Arquitectura, Universidad de Chile. Disponible en: https://web.uchile.cl/vignette/revista urbanismo/CDA/urb_complex/0,1311,SCID\%253D19141\%2526ISID\%253D668\%2526IDG\%253D2\%2526A CT\%253D0\%2526PRT\%253D19132,00.html

Fuschini Mejia, M. (1998) El agua en las llanuras. En Durán, D. (compiladora). La Argentina Ambiental. Naturaleza y Sociedad. Buenos Aires: Lugar.

García, R. (2006). Sistemas complejos: conceptos, método y fundamentación epistemológica de la investigación interdisciplinaria. Barcelona: Editorial Gedisa.

González, S., Torchia, N. y Viand, J. (2015). Inundaciones urbanas, En: Secretaría de Ambiente y Desarrollo Sustentable. Inundaciones urbanas y cambio climático: Recomendaciones para la gestión, Ciudad Autónoma de Buenos Aires, 33-47.

HEC-RAS (2016a). River Analysis System. User's Manual. Version 5.0. US Army Corps of Engineers Institute for Water Resources. Hydrologic Engineering Center. Davis. Disponible en: www.hec.usace.army.mil. 
HEC-RAS. (2016b). River Analysis System. 2D Modeling. User's Manual. US Army Corps of Engineers. Institute for Water Resources. Hydrologic Engineering Center. Davis. Disponible en: www.hec.usace.army.mil.

Henríquez Ruiz, C. (2009). El proceso de urbanización en la cuenca del río Chillán y su capacidad adaptativa ante precipitaciones extremas. Estudios Geográficos, LXX, (266), 155-179.

Herzer, H.; Rodríguez, Carla.; Celis, A.; Bartolomé, M. y Caputo, G. (2002). Convivir con el riesgo o la gestión del riesgo. LA RED. Disponible en: https://www.researchgate.net/profile/Alejandra_Celis/publication/ 237638971_CONVIVIR_CON_EL_RIESGO_O_LA_GESTION_DEL_RIESGO1/links/5591847c08ae1e1f9baff7 84.pdf

Johnston, R. J.; Gregory, D.; Smith, D. (1987). Diccionario de Geografía Humana, Madrid: Alianza.

La Macchia, M.L. (2015). Modelización y análisis espacial del drenaje urbano de la ciudad de Tandil mediante Tecnologías de la información Geográfica. Tesis de Licenciatura en Geografía. Universidad Nacional del Centro de la Provincia de Buenos Aires.

Linares, S. (2012). Análisis y modelización de la segregación socioespacial en ciudades medias bonaerenses mediante Sistemas de Información Geográfica: Pergamino, Olavarría y Tandil (1991-2001). Revista Geográfica de Valparaíso, Instituto de Geografía, Pontificia Universidad Católica de Valparaíso. Valparaíso (Chile), (45), 3-22.

Linares, S.; Picone, N. (2018). Application of Remote Sensing and Cellular Automata Model to Analyze and Simulate Urban Density Changes. En Qihao Weng. Edited by Qihao Weng, Dale Quattrochi, and Paolo E. Gamba. Chapter 10. Urban Remote Sensing. Second Edition. Remote Sensing Applications. Series Editor, 213-228. Indiana, USA: Indiana State University. Terre Haute.

López Trigal, Lorenzo (Dir.) (2015). Diccionario de Geografía aplicada y profesional. Terminología de análisis, planificación y gestión del territorio. Ed. Universidad de León.

Melesse, A.; Wang, X. (2007). Impervious Surface Area Dynamics and Storm Runoff Response. Remote Sensing of Impervious Surfaces, 369-384.

Natenzon, C. (1998). Riesgo, vulnerabilidad e incertidumbre. Desastres por inundaciones en Argentina. PIRNA. Facultad de Filosofía y Letras. UBA.

Pereyra A. (2014). El riesgo a las inundaciones en la trama de los eventos extremos. En Carballo, T.; Goldberg, S. Comunidad e información ambiental del riesgo. Las inundaciones y el Río Luján. Buenos Aires: Editorial Dunken. 13-26.

Sánchez, F. J. y Lastra, J., coords (2011). Guía metodológica para el desarrollo del Sistema Nacional de Cartografía de Zonas Inundables. Madrid: Ministerio de Medio Ambiente y Medio Rural y Marino.

Scioli, C. (2009). Modelación del escurrimiento superficial en áreas de llanura: Implementación y calibración de un modelo distribuido de grilla. Maestría en Recursos Hídricos en zonas de llanura. Facultad de Ciencias Exactas, Ingeniería y Agrimensura. Universidad Nacional del Rosario. 
Tucci, C. (2005). Gestão de inundações urbanas. Porto Alegre: UNESCO-PHI.

Vanneuville W., De Maeyer Ph., Maeghe K. \& Mostaert F. (2003). Model the effects of a flood in the Dender catchment, based on a risk methodology. Society of Cartography Bulletin, 37 (2), 59-64.

\section{LOS AUTORES}

María Lorena La Macchia Es Técnica en SIG, Profesora y Licenciada en Geografía, títulos otorgados por la Facultad de Ciencias Humanas de la Universidad Nacional del Centro de la provincia de Buenos Aires (FCHUNCPBA). Desde el año 2009 forma parte del Centro de Investigaciones Geográficas (CIG-FCH- UNCPBA) aportando y publicando diversos trabajos sobre distintas áreas que vinculan a la Geografía aplicada y las potencialidades de las TIG a problemas urbanos, como así también, participando en proyectos de Extensión y Transferencia del CIG-FCH- UNCPBA.

En el año 2015 ingresó a la carrera de Personal de Apoyo en Investigación (CPA-CONICET) en el Instituto de Geografía, Historia y Ciencias Sociales (IGEHCS).

Actualmente es Maestranda de la Maestría en Teledetección y SIG de la Facultad de Agronomía de la ciudad de Azul, Buenos Aires (FAA-UNCPBA) y se encuentra trabajando sobre la modelización de escenarios de riesgo de inundaciones mediante el aporte de las TIG y la ingeniería hidráulica e hidrodinámica a la cuenca urbana de la ciudad de Tandil.

llamacchia@fch.unicen.edu.ar

Santiago Linares Es profesor de Geografía, magister en Teledetección y Sistemas de Información Geográfica por la Universidad Nacional del Centro de la Provincia de Buenos Aires (UNCPBA) y Doctor en Geografía por la Universidad Nacional del Sur (UNS). Sus temas de investigación son referidos a la modelización y análisis del espacio urbano y aplicaciones de Sistemas de Información Geográfica a la investigación en Geografía y a diversas esferas de la planificación territorial. Es Investigador Adjunto del Consejo Nacional de Investigaciones Científicas y Técnicas (CONICET) de Argentina. Integrante del Instituto de Geografía, Historia y Ciencias Sociales (IGEHCS) dependiente de CONICET-UNCPBA. Docente del Departamento de Geografía de la Facultad de Ciencias Humanas (UNCPBA), a cargo de las cátedras relacionadas a la aplicación de Tecnologías de la Información Geográfica y análisis espacial cuantitativo. Director de la Revista Estudios Socioterritoriales. Participa en diversos proyectos de investigación acreditados institucionalmente, ha dictado numerosos cursos de capacitación y postgrado sobre investigación y análisis espacial con SIG, participa como miembro de redes nacionales e internacionales sobre Sistemas de Información Geografía, como así también, es responsable de proyectos de extensión y transferencia donde se aplican las geotecnologías a la solución de problemas socioeconómicos y ambientales en diversos municipios de la Argentina.

slinares@fch.unicen.edu.ar 